\title{
A 2.5D coupled FE-BE methodology for the dynamic interaction between longitudinally invariant structures and a layered halfspace
}

\author{
S. François ${ }^{\mathrm{a}}$, M. Schevenels ${ }^{\mathrm{a}}$, P. Galvín ${ }^{\mathrm{a}, \mathrm{b}}$, G. Lombaert ${ }^{\mathrm{a}}$, G. Degrande ${ }^{\mathrm{a}}$ \\ ${ }^{a}$ Department of Civil Engineering, K.U.Leuven, Kasteelpark Arenberg 40, B-3001 Leuven, Belgium \\ ${ }^{b}$ Escuela Técnica Superior de Ingenieros, Universidad de Sevilla, Camino de los Descubrimientos, E-41092 Sevilla, Spain
}

\begin{abstract}
This paper presents a general 2.5D coupled finite element - boundary element methodology for the computation of the dynamic interaction between a layered soil and structures with a longitudinally invariant geometry, such as railway tracks, roads, tunnels, dams, and pipelines. The classical 2.5D finite element method is combined with a novel $2.5 \mathrm{D}$ boundary element method. A regularized 2.5D boundary integral equation is derived that avoids the evaluation of singular traction integrals. The 2.5D Green's functions of a layered halfspace, computed with the direct stiffness method, are used in a boundary element method formulation. This avoids meshing of the free surface and the layer interfaces with boundary elements and effectively reduces the computational efforts and storage requirements. The proposed technique is applied to four examples: a road on the surface of a halfspace, a tunnel embedded in a layered halfspace, a dike on a halfspace and a vibration isolating screen in the soil.
\end{abstract}

Keywords: Boundary element method, elastodynamics, dynamic soil-structure interaction, 2.5D modelling

\section{Introduction}

The calculation of three-dimensional dynamic soil-structure interaction problems is computationally demanding, since the radiation of waves towards infinity has to be taken into account $[4,27]$. A number of assumptions is often made to reduce the computational efforts. In many cases, the geometry can be assumed to be periodic or longitudinally invariant, which is a valid assumption for roads, railway tracks, tunnels, dams, vibration isolation screens in the soil, pipelines, and alluvial valleys.

For periodic structures, a Floquet transform can be used for the computation of the structural response and the radiated wavefield $[8,16]$. In the case of longitudinally invariant structures, a computationally efficient two-and-a-half-dimensional (2.5D) approach can be applied $[3,17,35]$, where the Fourier transform of the longitudinal coordinate allows to represent the three-dimensional (3D) response of the structure and the radiated wavefield on a two-dimensional mesh. 2.5D boundary elements are often used for the soil $[30,33,34]$ while $2.5 \mathrm{D}$ finite elements are used for the structure [14, 15]. A number of examples involving railway tracks have been presented by Sheng et al. [30]. Andersen and Nielsen apply the methodology to study the effect of vibration isolating screens along a railway track $[1,2]$. A similar approach is followed by Lombaert and Degrande [24] and Lombaert et al. [25] to predict vibrations induced by road [24] and railway traffic [25]. The latter model has been validated by means of field measurements [25] and has been used to assess the vibration isolation efficiency of a floating slab track [26].

The classical 2.5D boundary element method applied to embedded structures requires Cauchy principal value integrals of the singular fundamental tractions. For the evaluation of these Cauchy principal value integrals, a fully or locally enclosing elements technique [9] or an analytical integration [31] can be used.

In the present paper, a regularized boundary integral equation is used as an alternative to the evaluation of singular integrals. This global regularization of the boundary integral equation is based on the fact that

Email address: stijn.francois@bwk.kuleuven.be (S. François)

Preprint submitted to Computer Methods in Applied Mechanics and Engineering

Published version: http://dx.doi.org/10.1016/j.cma.2010.01.001 
the singularity of the static and dynamic fundamental solutions correspond at the source point $[5,7,28]$. This requires a generalization of the global regularization technique to the $2.5 \mathrm{D}$ boundary integral equation, allowing for regular integration.

In most cases, the boundary element method is based on the 2.5D fundamental solution of a homogeneous full space, for which a closed form analytical expression is available [33, 34]. The use of the homogeneous full space solution has the disadvantage that the free surface and the layer interfaces of the halfspace have to be discretized with boundary elements. Meshing of the infinite free surface and the interfaces of the halfspace requires mesh truncation, at which spurious reflections may occur. These spurious reflections can be partially mitigated through the use of a special truncation element [30].

In the present paper, fundamental solutions of a layered halfspace are used in a $2.5 \mathrm{D}$ boundary element formulation as an alternative to the homogeneous full space solution. The layer interfaces and the surface of the halfspace no longer have to be meshed, avoiding spurious reflections at mesh truncations. The boundary element mesh can be limited to the interface between the structure and the soil, significantly reducing the size of the boundary element mesh.

The paper is organized as follows. Section 2 treats the 2.5D finite element formulation starting from the virtual work equation of the structure. In section 3 , the $2.5 \mathrm{D}$ boundary element method is discussed with emphasis on the global regularization technique and the use of fundamental solutions of a layered halfspace. The solution of the coupled finite element - boundary element problem is the topic of section 4 . The proposed methodology is demonstrated in section 5 for a road on a halfspace, a tunnel embedded in a layered halfspace, a dike on a halfspace and a vibration isolating screen.

\section{2.5D finite element formulation}

\subsection{Problem outline and domain decomposition}

A domain decomposition method is used to solve the problem involving a structure $\Omega_{\mathrm{b}}$ and a semi-infinite layered soil $\Omega_{\mathrm{s}}$ (figure 1). The dynamic soil-structure interaction problem is solved by enforcing continuity of displacements and equilibrium of stresses on the interface $\Sigma_{\mathrm{bs}}$ between both subdomains. The section $A_{\mathrm{b}}$ of the structure is invariant with respect to the longitudinal coordinate $y$. The dynamic soil-structure interaction problem is assumed to be linear and all equations are elaborated in the frequency domain. The dynamic equilibrium equation of the structure is discretized by means of $2.5 \mathrm{D}$ finite elements. The structure is considered as a $3 \mathrm{D}$ continuum, and can be modelled with $2.5 \mathrm{D}$ volume elements.

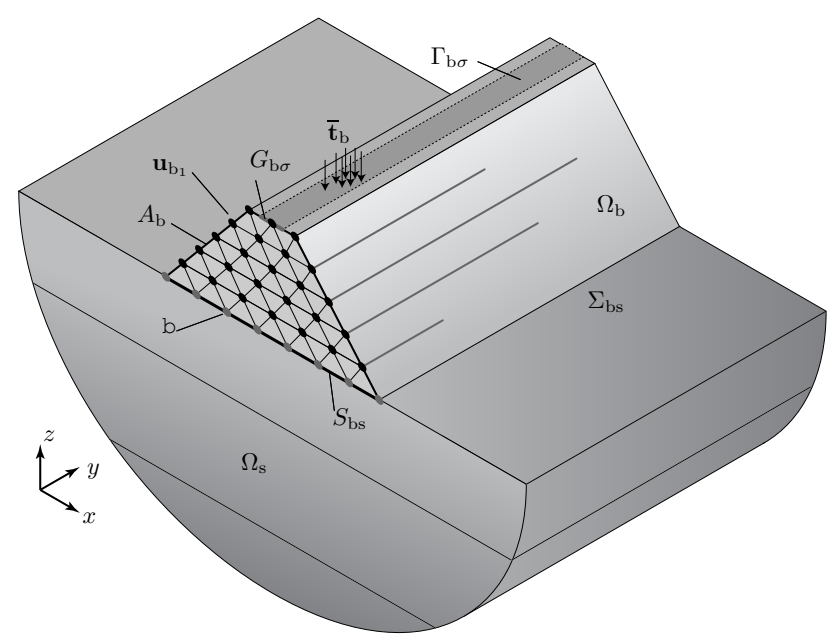

Figure 1: The geometry of the coupled soil-structure system. 


\subsection{Virtual work equation}

The equilibrium equation for the dynamic soil-structure interaction problem is formulated in a variational form. For any virtual displacement field $\mathbf{v}_{\mathrm{b}}$ imposed on the structure $\Omega_{\mathrm{b}}$, the sum of the virtual work of the internal and the inertial forces is equal to the virtual work of the external loads:

$$
-\omega^{2} \int_{\Omega_{\mathrm{b}}} \mathbf{v}_{\mathrm{b}} \cdot \rho_{\mathrm{b}} \mathbf{u}_{\mathrm{b}} d \Omega+\int_{\Omega_{\mathrm{b}}} \epsilon_{\mathrm{b}}\left(\mathbf{v}_{\mathrm{b}}\right): \boldsymbol{\sigma}_{\mathrm{b}}\left(\mathbf{u}_{\mathrm{b}}\right) d \Omega=\int_{\Omega_{\mathrm{b}}} \mathbf{v}_{\mathrm{b}} \cdot \rho_{\mathrm{b}} \mathbf{b}_{\mathrm{b}} d \Omega+\int_{\Gamma_{\mathrm{b} \sigma}} \mathbf{v}_{\mathrm{b}} \cdot \overline{\mathbf{t}}_{\mathrm{b}}^{\mathbf{n}_{\mathrm{b}}} d \Gamma+\int_{\Sigma_{\mathrm{bs}}} \mathbf{v}_{\mathrm{b}} \cdot \mathbf{t}_{\mathrm{b}}^{n_{\mathrm{b}}}\left(\mathbf{u}_{\mathrm{b}}\right) d \Gamma
$$

where $\mathbf{u}_{\mathrm{b}}(\mathbf{x}, \omega)$ is the displacement vector in the structure containing three displacement components. $\rho_{\mathrm{b}} \mathbf{b}_{\mathrm{b}}$ denotes the body force in the domain $\Omega_{\mathrm{b}}$ and $\mathbf{t}_{\mathrm{b}}^{\mathbf{n}_{\mathrm{b}}}=\boldsymbol{\sigma}_{\mathrm{b}} \cdot \mathbf{n}_{\mathrm{b}}$ is the traction vector on a boundary with unit outward normal vector $\mathbf{n}_{\mathrm{b}}$. Tractions $\overline{\mathbf{t}}_{\mathrm{b}}^{\mathbf{n}_{\mathrm{b}}}$ are imposed on the boundary $\Gamma_{\mathrm{b} \sigma}$ (figure 1 ).

Accounting for the equilibrium of stresses $\mathbf{t}_{\mathrm{b}}^{\mathbf{n}_{\mathrm{b}}}\left(\mathbf{u}_{\mathrm{b}}\right)+\mathbf{t}_{\mathrm{s}}^{\mathbf{n}_{\mathrm{s}}}\left(\mathbf{u}_{\mathrm{s}}\right)=0$ on the interface $\Sigma_{\mathrm{bs}}$, where $\mathbf{u}_{\mathrm{s}}(\mathbf{x}, \omega)$ is the displacement vector in the soil and $\mathbf{t}_{\mathrm{s}}^{\mathbf{n}_{\mathrm{s}}}=\boldsymbol{\sigma}_{\mathrm{s}} \cdot \mathbf{n}_{\mathrm{s}}$ is the traction vector on a boundary with unit outward normal $\mathbf{n}_{\mathrm{s}}$, equation (1) becomes:

$$
-\omega^{2} \int_{\Omega_{\mathrm{b}}} \mathbf{v}_{\mathrm{b}} \cdot \rho_{\mathrm{b}} \mathbf{u}_{\mathrm{b}} d \Omega+\int_{\Omega_{\mathrm{b}}} \boldsymbol{\epsilon}_{\mathrm{b}}\left(\mathbf{v}_{\mathrm{b}}\right): \boldsymbol{\sigma}_{\mathrm{b}}\left(\mathbf{u}_{\mathrm{b}}\right) d \Omega=\int_{\Omega_{\mathrm{b}}} \mathbf{v}_{\mathrm{b}} \cdot \rho_{\mathrm{b}} \mathbf{b}_{\mathrm{b}} d \Omega+\int_{\Gamma_{\mathrm{b} \sigma}} \mathbf{v}_{\mathrm{b}} \cdot \overline{\mathbf{t}}_{\mathrm{b}}^{\mathbf{n}_{\mathrm{b}}} d \Gamma-\int_{\Sigma_{\mathrm{bs}}} \mathbf{v}_{\mathrm{b}} \cdot \mathbf{t}_{\mathrm{s}}^{\mathbf{n}_{\mathrm{s}}}\left(\mathbf{u}_{\mathrm{s}}\right) d \Gamma
$$

An alternative vector notation for the symmetrical stress tensor $\sigma_{\mathrm{b}}$ is used where the components are collected in the vector $\boldsymbol{\sigma}_{\mathrm{b}}=\left\{\sigma_{x x}, \sigma_{y y}, \sigma_{z z}, \sigma_{x y}, \sigma_{y z}, \sigma_{z x}\right\}^{\mathrm{T}}$. Analogously, the vector $\boldsymbol{\epsilon}_{\mathrm{b}}=\left\{\epsilon_{x x}, \epsilon_{y y}, \epsilon_{z z}, \gamma_{x y}, \gamma_{y z}, \gamma_{z x}\right\}^{\mathrm{T}}$ collects the components of the symmetrical strain tensor $\epsilon_{\mathrm{b}}$; the use of engineering shear strains allows to write the internal work as an inner product $\boldsymbol{\epsilon}_{\mathrm{b}}^{\mathrm{T}} \boldsymbol{\sigma}_{\mathrm{b}}$.

Next, the finite element discretization is introduced into equation (2). As the structure is longitudinally invariant and has an invariant cross section $A_{\mathrm{b}}$, the displacement vector $\mathbf{u}_{\mathrm{b}}(\mathbf{x}, \omega)$ is discretized as:

$$
\mathbf{u}_{\mathrm{b}}(\mathbf{x}, \omega) \simeq \mathbf{N}_{\mathrm{b}}(x, z) \underline{\mathbf{u}}_{\mathrm{b}}(y, \omega)
$$

where $\mathbf{N}_{\mathrm{b}}(x, z)$ are the globally defined shape functions defined over the section $A_{\mathrm{b}}$ and $\underline{\mathbf{u}}_{\mathrm{b}}(y, \omega)$ is the vector with the degrees of freedom at all nodes of the two-dimensional mesh. The vector $\underline{\mathbf{u}}_{\mathrm{b}}(y, \omega)$ is a function of the longitudinal coordinate $y$ and the frequency $\omega$.

The strain vector $\boldsymbol{\epsilon}_{\mathrm{b}}$ is derived from the displacement vector $\underline{\mathbf{u}}_{\mathrm{b}}(y, \omega)$ as:

$$
\boldsymbol{\epsilon}_{\mathrm{b}}=\mathbf{L}_{1} \mathbf{N}_{\mathrm{b}} \underline{\mathbf{u}}_{\mathrm{b}}+\mathbf{L}_{2} \mathbf{N}_{\mathrm{b}} \frac{\partial \underline{\mathbf{u}}_{\mathrm{b}}}{\partial y}
$$

where:

$$
\mathbf{L}_{1}=\left[\begin{array}{ccc}
\frac{\partial}{\partial x} & 0 & 0 \\
0 & 0 & 0 \\
0 & 0 & \frac{\partial}{\partial z} \\
0 & \frac{\partial}{\partial x} & 0 \\
0 & \frac{\partial}{\partial z} & 0 \\
\frac{\partial}{\partial z} & 0 & \frac{\partial}{\partial x}
\end{array}\right] \quad \text { and } \quad \mathbf{L}_{2}=\left[\begin{array}{ccc}
0 & 0 & 0 \\
0 & 1 & 0 \\
0 & 0 & 0 \\
1 & 0 & 0 \\
0 & 0 & 1 \\
0 & 0 & 0
\end{array}\right]
$$

The strain vector $\epsilon_{\mathrm{b}}$ in equation (4) is related to both the displacement vector $\mathbf{u}_{\mathrm{b}}$ and its derivative $\partial \mathbf{u}_{\mathrm{b}} / \partial y$ with respect to the longitudinal coordinate $y$. This differs from the relationship $\boldsymbol{\epsilon}_{\mathrm{b}}=\mathbf{L N}_{\mathrm{b}} \mathbf{u}_{\mathrm{b}}$ in the case of 3D finite elements, where the strain vector is written as a linear combination of the elements of the displacement vector $\mathbf{u}_{\mathrm{b}}$ only. Equation (4) is alternatively written as:

$$
\boldsymbol{\epsilon}_{\mathrm{b}}=\mathbf{B}_{\mathrm{b} 1} \underline{\mathbf{u}}_{\mathrm{b}}+\mathbf{B}_{\mathrm{b} 2} \frac{\partial \underline{\mathbf{u}}_{\mathrm{b}}}{\partial y}
$$

where $\mathbf{B}_{\mathrm{b} 1}=\mathbf{L}_{1} \mathbf{N}_{\mathrm{b}}$ and $\mathbf{B}_{\mathrm{b} 2}=\mathbf{L}_{2} \mathbf{N}_{\mathrm{b}}$.

The stress vector is related to the strain vector through the constitutive relation:

$$
\sigma_{\mathrm{b}}=\mathrm{C}_{\mathrm{b}} \epsilon_{\mathrm{b}}
$$


where, in the case of a linear isotropic material, the constitutive matrix $\mathbf{C}_{\mathrm{b}}$ depends on the Lamé coefficients $\lambda$ and $\mu$.

A standard Galerkin procedure is followed, where the same approximation is used for the virtual displacement vector $\mathbf{v}_{\mathrm{b}}(\mathbf{x}, \omega)=\mathbf{N}_{\mathrm{b}}(x, z) \mathbf{v}_{\mathrm{b}}(y, \omega)$ as for the displacement vector $\mathbf{u}_{\mathrm{b}}(\mathbf{x}, \omega)$. Substituting the strain-displacement relation (6) and the constitutive equation (7) in the virtual work equation (2) yields:

$$
\begin{array}{r}
-\omega^{2} \int_{\Omega_{\mathrm{b}}} \underline{\mathbf{v}}_{\mathrm{b}}^{\mathrm{T}} \mathbf{N}_{\mathrm{b}}^{\mathrm{T}} \rho_{\mathrm{b}} \mathbf{N}_{\mathrm{b}} \underline{\mathbf{u}}_{\mathrm{b}} d \Omega+\int_{\Omega_{\mathrm{b}}}\left(\underline{\mathbf{v}}_{\mathrm{b}}^{\mathrm{T}} \mathbf{B}_{\mathrm{b} 1}^{\mathrm{T}}+\left(\frac{\partial \underline{\mathbf{v}_{\mathrm{b}}}}{\partial y}\right)^{\mathrm{T}} \mathbf{B}_{\mathrm{b} 2}^{\mathrm{T}}\right) \mathbf{C}_{\mathrm{b}}\left(\mathbf{B}_{\mathrm{b} 1} \underline{\mathbf{u}}_{\mathrm{b}}+\mathbf{B}_{\mathrm{b} 2} \frac{\partial \underline{\mathbf{u}_{\mathrm{b}}}}{\partial y}\right) d \Omega \\
=\int_{\Omega_{\mathrm{b}}} \underline{\mathbf{v}}_{\mathrm{b}}^{\mathrm{T}} \mathbf{N}_{\mathrm{b}}^{\mathrm{T}} \rho_{\mathrm{b}} \mathbf{b}_{\mathrm{b}} d \Omega+\int_{\Gamma_{\mathrm{b} \sigma}} \underline{\mathbf{v}}_{\mathrm{b}}^{\mathrm{T}} \mathbf{N}_{\mathrm{b}}^{\mathrm{T}} \overline{\mathbf{t}}_{\mathrm{b}}^{\mathbf{n}_{\mathrm{b}}} d \Gamma-\int_{\Sigma_{\mathrm{bs}}} \underline{\mathbf{v}}_{\mathrm{b}}^{\mathrm{T}} \mathbf{N}_{\mathrm{b}}^{\mathrm{T}} \mathbf{t}_{\mathrm{s}}^{\mathbf{n}_{\mathrm{s}}}\left(\mathbf{u}_{\mathrm{s}}\right) d \Gamma
\end{array}
$$

Equation (8) is further elaborated, rewriting the volume integrals as an integral over the longitudinal coordinate $y$ and the cross section $A_{\mathrm{b}}$ :

$$
\begin{aligned}
-\omega^{2} \int_{-\infty}^{\infty} \underline{\mathbf{v}}_{\mathrm{b}}^{\mathrm{T}}\left(\int_{A_{\mathrm{b}}} \mathbf{N}_{\mathrm{b}}^{\mathrm{T}} \rho_{\mathrm{b}} \mathbf{N}_{\mathrm{b}} d A\right) \underline{\mathbf{u}}_{\mathrm{b}} d y+\int_{-\infty}^{\infty} \underline{\mathbf{v}}_{\mathrm{b}}^{\mathrm{T}}\left(\int_{A_{\mathrm{b}}} \mathbf{B}_{\mathrm{b} 1}^{\mathrm{T}} \mathbf{C}_{\mathrm{b}} \mathbf{B}_{\mathrm{b} 1} d A\right) \underline{\mathbf{u}}_{\mathrm{b}} d y \\
+\int_{-\infty}^{\infty} \underline{\mathbf{v}}_{\mathrm{b}}^{\mathrm{T}}\left(\int_{A_{\mathrm{b}}} \mathbf{B}_{\mathrm{b} 1}^{\mathrm{T}} \mathbf{C}_{\mathrm{b}} \mathbf{B}_{\mathrm{b} 2} d A\right) \frac{\partial \underline{\mathbf{u}}_{\mathrm{b}}}{\partial y} d y+\int_{-\infty}^{\infty}\left(\frac{\partial \underline{\mathbf{v}}_{\mathrm{b}}}{\partial y}\right)^{\mathrm{T}}\left(\int_{A_{\mathrm{b}}} \mathbf{B}_{\mathrm{b} 2}^{\mathrm{T}} \mathbf{C}_{\mathrm{b}} \mathbf{B}_{\mathrm{b} 1} d A\right) \underline{\mathbf{u}}_{\mathrm{b}} d y \\
+\int_{-\infty}^{\infty}\left(\frac{\partial \underline{\mathbf{v}} \mathrm{b}}{\partial y}\right)^{\mathrm{T}}\left(\int_{A_{\mathrm{b}}} \mathbf{B}_{\mathrm{b} 2}^{\mathrm{T}} \mathbf{C}_{\mathrm{b}} \mathbf{B}_{\mathrm{b} 2} d A\right) \frac{\partial \underline{\mathbf{u}}_{\mathrm{b}}}{\partial y} d y=\int_{-\infty}^{\infty} \underline{\mathbf{v}}_{\mathrm{b}}^{\mathrm{T}}\left(\int_{A_{\mathrm{b}}} \mathbf{N}_{\mathrm{b}}^{\mathrm{T}} \rho_{\mathrm{b}} \mathbf{b}_{\mathrm{b}} d A\right) d y \\
\quad+\int_{-\infty}^{\infty} \underline{\mathbf{v}}_{\mathrm{b}}^{\mathrm{T}}\left(\int_{G_{\mathrm{b} \sigma}} \mathbf{N}_{\mathrm{b}}^{\mathrm{T}} \overline{\mathbf{t}}_{\mathrm{b}}^{\mathbf{n}_{\mathrm{b}}} d \Gamma\right) d y-\int_{-\infty}^{\infty} \underline{\mathbf{v}}_{\mathrm{b}}^{\mathrm{T}}\left(\int_{S_{\mathrm{bs}}} \mathbf{N}_{\mathrm{b}}^{\mathrm{T}} \mathbf{t}_{\mathrm{s}}^{\mathbf{n}_{\mathrm{s}}}\left(\mathbf{u}_{\mathrm{s}}\right) d \Gamma\right) d y
\end{aligned}
$$

where $G_{\mathrm{b} \sigma}$ is the intersection of the surface $\Gamma_{\mathrm{b} \sigma}$ with the plane $y=0$ and $S_{\mathrm{bs}}$ is defined as the intersection of the soil-structure interface $\Sigma_{\mathrm{bs}}$ with the plane $y=0$ (figure 1). The discretized equation is obtained through elimination of the virtual displacement vector $\underline{\mathbf{v}}_{\mathrm{b}}(y, \omega)$. This requires integration by parts on the terms containing derivatives $\partial \underline{\mathbf{v}}_{\mathrm{b}}(y, \omega) / \partial y$ in equation $(9)$ :

$$
\begin{aligned}
& -\omega^{2} \int_{-\infty}^{\infty} \underline{\mathbf{v}}_{\mathrm{b}}^{\mathrm{T}}\left[\int_{A_{\mathrm{b}}} \mathbf{N}_{\mathrm{b}}^{\mathrm{T}} \rho_{\mathrm{b}} \mathbf{N}_{\mathrm{b}} d A\right] \underline{\mathbf{u}}_{\mathrm{b}} d y+\int_{-\infty}^{\infty} \underline{\mathbf{v}}_{\mathrm{b}}^{\mathrm{T}}\left[\int_{A_{\mathrm{b}}} \mathbf{B}_{\mathrm{b} 1}^{\mathrm{T}} \mathbf{C}_{\mathrm{b}} \mathbf{B}_{\mathrm{b} 1} d A\right] \underline{\mathbf{u}}_{\mathrm{b}} d y \\
& +\int_{-\infty}^{\infty} \underline{\mathbf{v}}_{\mathrm{b}}^{\mathrm{T}}\left[\int_{A_{\mathrm{b}}} \mathbf{B}_{\mathrm{b} 1}^{\mathrm{T}} \mathbf{C}_{\mathrm{b}} \mathbf{B}_{\mathrm{b} 2} d A-\int_{A_{\mathrm{b}}} \mathbf{B}_{\mathrm{b} 2}^{\mathrm{T}} \mathbf{C}_{\mathrm{b}} \mathbf{B}_{\mathrm{b} 1} d A\right] \frac{\partial \underline{\mathbf{u}}_{\mathrm{b}}}{\partial y} d y-\int_{-\infty}^{\infty} \underline{\mathbf{v}}_{\mathrm{b}}^{\mathrm{T}}\left[\int_{A_{\mathrm{b}}} \mathbf{B}_{\mathrm{b} 2}^{\mathrm{T}} \mathbf{C}_{\mathrm{b}} \mathbf{B}_{\mathrm{b} 2} d A\right] \frac{\partial^{2} \underline{\mathbf{u}}_{\mathrm{b}}}{\partial y^{2}} d y \\
& =\int_{-\infty}^{\infty} \underline{\mathbf{v}}_{\mathrm{b}}^{\mathrm{T}}\left[\int_{A_{\mathrm{b}}} \mathbf{N}_{\mathrm{b}}^{\mathrm{T}} \rho_{\mathrm{b}} \mathbf{b}_{\mathrm{b}} d A\right] d y+\int_{-\infty}^{\infty} \underline{\mathbf{v}}_{\mathrm{b}}^{\mathrm{T}}\left[\int_{G_{\mathrm{b} \sigma}} \mathbf{N}_{\mathrm{b}}^{\mathrm{T}} \overline{\mathbf{t}}_{\mathrm{b}}^{\mathbf{n}_{\mathrm{b}}} d \Gamma\right] d y-\int_{-\infty}^{\infty} \underline{\mathbf{v}}_{\mathrm{b}}^{\mathrm{T}}\left[\int_{S_{\mathrm{bs}}} \mathbf{N}_{\mathrm{b}}^{\mathrm{T}} \mathbf{t}_{\mathrm{s}}^{\mathbf{n}_{\mathrm{s}}}\left(\mathbf{u}_{\mathrm{s}}\right) d \Gamma\right] d y \quad(10)
\end{aligned}
$$

Since equation (10) holds for any virtual displacement $\underline{\mathbf{v}}_{\mathrm{b}}(y, \omega)$, all integrals over the longitudinal coordinate $y$ vanish and equation (10) is equivalent to:

$$
-\omega^{2} \mathbf{M}_{\mathrm{bb}} \underline{\mathbf{u}}_{\mathrm{b}}(y, \omega)+\mathbf{K}_{\mathrm{bb}}^{0} \underline{\mathbf{u}}_{\mathrm{b}}(y, \omega)+\mathbf{K}_{\mathrm{bb}}^{1} \frac{\partial \underline{\mathbf{u}}_{\mathrm{b}}(y, \omega)}{\partial y}+\mathbf{K}_{\mathrm{bb}}^{2} \frac{\partial^{2} \underline{\mathbf{u}}_{\mathrm{b}}(y, \omega)}{\partial y^{2}}=\underline{\mathbf{f}}_{\mathrm{b}}(y, \omega)+\underline{\mathbf{f}}_{\mathrm{b}}^{\mathrm{s}}(y, \omega)
$$

where the mass matrix $\mathbf{M}_{\mathrm{bb}}$ is defined as:

$$
\mathbf{M}_{\mathrm{bb}}=\int_{A_{\mathrm{b}}} \mathbf{N}_{\mathrm{b}}^{\mathrm{T}} \rho_{\mathrm{b}} \mathbf{N}_{\mathrm{b}} d A
$$


The stiffness matrices $\mathbf{K}_{\mathrm{bb}}^{0}, \mathbf{K}_{\mathrm{bb}}^{1}$, and $\mathbf{K}_{\mathrm{bb}}^{2}$ are defined as:

$$
\begin{aligned}
\mathbf{K}_{\mathrm{bb}}^{0} & =\int_{A_{\mathrm{b}}} \mathbf{B}_{\mathrm{b} 1}^{\mathrm{T}} \mathbf{C}_{\mathrm{b}} \mathbf{B}_{\mathrm{b} 1} d A \\
\mathbf{K}_{\mathrm{bb}}^{1} & =\int_{A_{\mathrm{b}}}\left(\mathbf{B}_{\mathrm{b} 1}^{\mathrm{T}} \mathbf{C}_{\mathrm{b}} \mathbf{B}_{\mathrm{b} 2}-\mathbf{B}_{\mathrm{b} 2}^{\mathrm{T}} \mathbf{C}_{\mathrm{b}} \mathbf{B}_{\mathrm{b} 1}\right) d A \\
\mathbf{K}_{\mathrm{bb}}^{2} & =\int_{A_{\mathrm{b}}} \mathbf{B}_{\mathrm{b} 2}^{\mathrm{T}} \mathbf{C}_{\mathrm{b}} \mathbf{B}_{\mathrm{b} 2} d A
\end{aligned}
$$

The external load vector:

$$
\underline{\mathbf{f}}_{\mathrm{b}}(y, \omega)=\int_{A_{\mathrm{b}}} \mathbf{N}_{\mathrm{b}}^{\mathrm{T}} \rho_{\mathrm{b}} \mathbf{b}_{\mathrm{b}}(x, y, z, \omega) d A+\int_{G_{\mathrm{b} \sigma}} \mathbf{N}_{\mathrm{b}}^{\mathrm{T}} \overline{\mathbf{t}}_{\mathrm{b}}^{\mathbf{n}_{\mathrm{b}}}(x, y, z, \omega) d \Gamma
$$

contains contributions of both body forces and surface tractions and is evaluated for every point $y$ on the longitudinal axis. The force vector:

$$
\underline{\mathbf{f}}_{\mathrm{b}}^{\mathrm{s}}(y, \omega)=-\int_{S_{\mathrm{bs}}} \mathbf{N}_{\mathrm{b}}^{\mathrm{T}} \mathbf{t}_{\mathrm{s}}^{\mathbf{n}_{\mathrm{s}}}\left(\mathbf{u}_{\mathrm{s}}(x, y, z, \omega)\right) d \Gamma
$$

represents the soil-structure interaction forces on the interface $\Sigma_{\mathrm{bs}}$.

The integrals in equations (12)-(15) are evaluated by means of a classical two-dimensional Gaussian integration. The matrices $\mathbf{M}_{\mathrm{bb}}$ and $\mathbf{K}_{\mathrm{bb}}^{0}$ correspond to a combination of the classical two-dimensional inplane and out-of-plane finite element mass and stiffness matrices, respectively. For the mass matrix $\mathbf{M}_{\mathrm{bb}}$ and the stiffness matrix $\mathbf{K}_{\mathrm{bb}}^{0}$, the in-plane displacements $u_{x}$ and $u_{z}$ are uncoupled from the out-of-plane displacements $u_{y}$. The stiffness matrices $\mathbf{K}_{\mathrm{bb}}^{1}$ and $\mathbf{K}_{\mathrm{bb}}^{2}$ account for $3 \mathrm{D}$ wave propagation in the structure, where the in-plane and out-of plane degrees of freedom are coupled.

The differential equation (11) is solved by a Fourier transform of the longitudinal coordinate $y$ to the horizontal wavenumber $k_{y}$, where the Fourier transform is defined as $\mathcal{F}\left[f(y), k_{y}\right]=\int_{-\infty}^{\infty} \exp \left(+i k_{y} y\right) f(y) d y$. Equation (11) is transformed to the wavenumber domain as:

$$
\left[-\omega^{2} \mathbf{M}_{\mathrm{bb}}+\mathbf{K}_{\mathrm{bb}}^{0}-i k_{y} \mathbf{K}_{\mathrm{bb}}^{1}-k_{y}^{2} \mathbf{K}_{\mathrm{bb}}^{2}\right] \underline{\mathbf{u}}_{\mathrm{b}}\left(k_{y}, \omega\right)=\underline{\tilde{\mathbf{f}}}_{\mathrm{b}}\left(k_{y}, \omega\right)+\underline{\tilde{\mathbf{f}}}_{\mathrm{b}}^{\mathrm{s}}\left(k_{y}, \omega\right)
$$

where a tilde above a variable denotes its representation in the frequency-wavenumber domain.

In equation (18), the force vector:

$$
\tilde{\mathbf{f}}_{\mathrm{b}}^{\mathrm{s}}\left(k_{y}, \omega\right)=-\int_{S_{\mathrm{bs}}} \mathbf{N}_{\mathrm{b}}^{\mathrm{T}} \tilde{\mathbf{t}}_{\mathrm{s}}^{\mathbf{n}_{\mathrm{s}}}\left(\tilde{\mathbf{u}}_{\mathrm{s}}\left(x, k_{y}, z, \omega\right)\right) d \Gamma
$$

is an integral of the product of the shape functions $\mathbf{N}_{\mathrm{b}}$ and the wavenumber-frequency representation $\tilde{\mathbf{t}}_{\mathrm{s}}\left(\tilde{\mathbf{u}}_{\mathrm{s}}\right)$ of the tractions on the soil-structure interface $\Sigma_{\mathrm{bs}}$. Accounting for continuity of displacements $\tilde{\mathbf{u}}_{\mathrm{s}}=\tilde{\mathbf{u}}_{\mathrm{b}}$ on the soil-structure interface $\Sigma_{\mathrm{bs}}$, and introducing the finite element discretization (3), equation (19) is elaborated as:

$$
\tilde{\tilde{\mathbf{f}}}_{\mathrm{b}}^{\mathrm{s}}\left(k_{y}, \omega\right)=-\int_{S_{\mathrm{bs}}} \mathbf{N}_{\mathrm{b}}^{\mathrm{T}} \tilde{\mathbf{t}}_{\mathrm{s}}^{\mathbf{n}_{\mathrm{s}}}\left(\mathbf{N}_{\mathrm{b}}\right)\left(x, k_{y}, z, \omega\right) \underline{\mathbf{u}}_{\mathrm{b}}\left(k_{y}, \omega\right) d \Gamma
$$

where $\tilde{\mathbf{t}}_{\mathrm{s}}^{\mathbf{n}_{\mathrm{s}}}\left(\mathbf{N}_{\mathrm{b}}\right)\left(x, k_{y}, z, \omega\right)$ represents the tractions $\tilde{\mathbf{t}}_{\mathrm{s}}^{\mathbf{n}_{\mathrm{s}}}\left(x, k_{y}, z, \omega\right)$ due to imposed displacements $\tilde{\mathbf{u}}_{\mathrm{b}}(x, z)=$ $\mathbf{N}_{\mathrm{b}}(x, z)$ on the soil-structure interface. Introducing equation (20) in the equilibrium equation (18) yields:

$$
\left[-\omega^{2} \mathbf{M}_{\mathrm{bb}}+\mathbf{K}_{\mathrm{bb}}^{0}-i k_{y} \mathbf{K}_{\mathrm{bb}}^{1}-k_{y}^{2} \mathbf{K}_{\mathrm{bb}}^{2}+\tilde{\mathbf{K}}_{\mathrm{bb}}^{\mathrm{s}}\left(k_{y}, \omega\right)\right] \underline{\tilde{\mathbf{u}}}_{\mathrm{b}}\left(k_{y}, \omega\right)=\tilde{\tilde{\mathbf{f}}}_{\mathrm{b}}\left(k_{y}, \omega\right)
$$

where

$$
\tilde{\mathbf{K}}_{\mathrm{bb}}^{\mathrm{s}}\left(k_{y}, \omega\right)=\int_{S_{\mathrm{bs}}} \mathbf{N}_{\mathrm{b}}^{\mathrm{T}} \tilde{\mathbf{t}}_{\mathrm{s}}^{\mathbf{n}_{\mathrm{s}}}\left(\mathbf{N}_{\mathrm{b}}\right)\left(x, k_{y}, z, \omega\right) d \Gamma
$$


represents the dynamic stiffness matrix of the soil in the wavenumber-frequency domain.

The derivation of the 2.5D finite element equilibrium equation (21) can similarly be performed for 2.5D shell elements or beam elements (figure 2). 2.5D shell elements have first been derived by Gavrić [14, 15] in a study of wave propagation in cylindrical thin-walled structures. The 2.5D shell element has three displacement degrees of freedom and one degree of freedom for the rotation around the $y$-axis (figure $2 \mathrm{~b}$ ). In the following, a shell element is based on Kirchhoff bending theory and in-plane plane stress deformation. The 2.5D beam element consists of a single node with four degrees of freedom: three displacement degrees of freedom and one degree of freedom for rotation around the $y$-axis (figure $2 \mathrm{c}$ ).

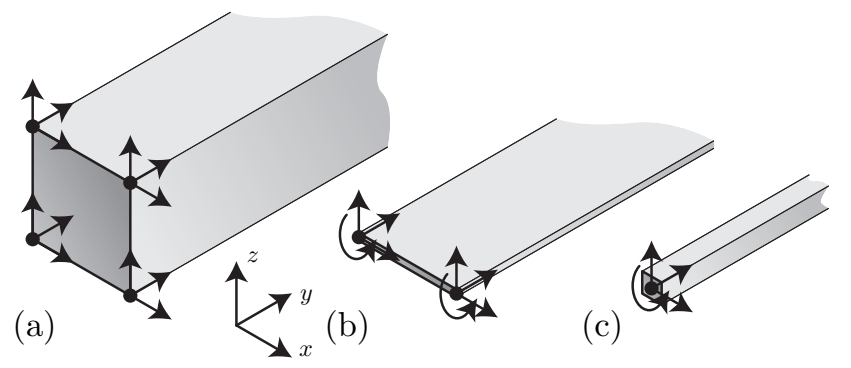

Figure 2: 2.5D finite elements: (a) a 2.5D finite volume element, (b) a 2.5D finite shell element, and (c) a 2.5D finite beam element.

A longitudinally invariant structure can be meshed using a combination of volume, beam, and shell elements. The assembly of $2.5 \mathrm{D}$ element stiffness matrices results in the following generalized 2.5D finite element equilibrium equation $[6,14,15]$ :

$$
\left[-\omega^{2} \mathbf{M}_{\mathrm{bb}}+\mathbf{K}_{\mathrm{bb}}^{0}-i k_{y} \mathbf{K}_{\mathrm{bb}}^{1}-k_{y}^{2} \mathbf{K}_{\mathrm{bb}}^{2}+i k_{y}^{3} \mathbf{K}_{\mathrm{bb}}^{3}+k_{y}^{4} \mathbf{K}_{\mathrm{bb}}^{4}+\tilde{\mathbf{K}}_{\mathrm{bb}}^{\mathrm{s}}\left(k_{y}, \omega\right)\right] \tilde{\mathbf{u}}_{\mathrm{b}}\left(k_{y}, \omega\right) \quad=\quad \tilde{\mathbf{f}}_{\mathrm{b}}\left(k_{y}, \omega\right)
$$

The finite element matrices $\mathbf{M}_{\mathrm{bb}}$ and $\mathbf{K}_{\mathrm{bb}}^{0}$ to $\mathbf{K}_{\mathrm{bb}}^{4}$ in equation (23) are independent of the wavenumber $k_{y}$ and the frequency $\boldsymbol{\omega}$, and are only assembled once.

\section{2.5D boundary element formulation}

\subsection{Integral representation theorem}

The 2.5D boundary element method is based on the integral equation that relates the displacements in the soil domain to the displacements and tractions on the soil-structure interface. The 2.5D boundary integral equation has been derived by Sheng et al. [31] from the 2.5D reciprocal theorem. In this paper, the $2.5 \mathrm{D}$ boundary integral equation is derived from the $3 \mathrm{D}$ integral representation [5]:

$$
\begin{aligned}
\kappa u_{\mathrm{s} i}\left(x^{\prime}, y^{\prime}, z^{\prime}, \omega\right)=\int_{\Sigma_{\mathrm{bs}}} u_{i j}^{\mathrm{G}}\left(x^{\prime}, y^{\prime}, z^{\prime}, x, y, z, \omega\right) t_{\mathrm{s} j}^{\mathbf{n}}(x, y, z, \omega) d \Gamma \\
\quad-\int_{\Sigma_{\mathrm{bs}}} t_{i j}^{\mathrm{Gn}}\left(x^{\prime}, y^{\prime}, z^{\prime}, x, y, z, \omega\right) u_{\mathrm{s} j}(x, y, z, \omega) d \Gamma=0
\end{aligned}
$$

that expresses the relation between the displacements $u_{\mathrm{s} i}(x, y, z, \omega)$ and tractions $t_{\mathrm{s} i}^{\mathbf{n}}(x, y, z, \omega)$ on the interface $\Sigma_{\mathrm{bs}}$ to the Green's displacements $u_{i j}^{\mathrm{G}}\left(x^{\prime}, y^{\prime}, z^{\prime}, x, y, z, \omega\right)$ and tractions $t_{i j}^{\mathrm{Gn}}\left(x^{\prime}, y^{\prime}, z^{\prime}, x, y, z, \omega\right)$. In equation (24), $\kappa$ is equal to 1 for points $\left\{x^{\prime}, y^{\prime}, z^{\prime}\right\}^{\mathrm{T}}$ inside the domain $\Omega_{\mathrm{s}}$ and equal to 0 for points $\left\{x^{\prime}, y^{\prime}, z^{\prime}\right\}^{\mathrm{T}}$ located outside the domain $\Omega_{\mathrm{s}}$. Integral equation (24) is not valid if the point $\left\{x^{\prime}, y^{\prime}, z^{\prime}\right\}^{\mathrm{T}}$ is located on the boundary $\Sigma_{\mathrm{bs}}$. 
Equation (24) is elaborated, rewriting the surface integrals as integrals over the intersection $S_{\mathrm{bs}}$ of the interface $\Sigma_{\mathrm{bs}}$ with the plane $y=0$ (figure 1) and integrals with respect to the longitudinal coordinate $y$ (figure 1):

$$
\begin{aligned}
\kappa u_{\mathrm{si}}\left(x^{\prime}, y^{\prime}, z^{\prime}, \omega\right)=\int_{S_{\mathrm{bs}}} \int_{-\infty}^{+\infty} u_{i j}^{\mathrm{G}}\left(x^{\prime}, y^{\prime}, z^{\prime}, x, y, z, \omega\right) t_{\mathrm{s} j}^{\mathbf{n}}(x, y, z, \omega) d y d S \\
\quad-\int_{S_{\mathrm{bs}}} \int_{-\infty}^{+\infty} t_{i j}^{\mathrm{Gn}}\left(x^{\prime}, y^{\prime}, z^{\prime}, x, y, z, \omega\right) u_{\mathrm{s} j}(x, y, z, \omega) d y d S
\end{aligned}
$$

It is assumed that the soil is invariant in the horizontal direction. As a result, the Green's functions only depend on the relative horizontal distance between source and receiver. In equation (25), the source is shifted to the plane $y=0$ :

$$
\begin{aligned}
\kappa u_{\mathrm{s} i}\left(x^{\prime}, y^{\prime}, z^{\prime}, \omega\right)=\int_{S_{\mathrm{bs}}} \int_{-\infty}^{+\infty} u_{i j}^{\mathrm{G}}\left(x^{\prime}, 0, z^{\prime}, x, y-y^{\prime}, z, \omega\right) t_{\mathrm{s} j}^{\mathrm{n}}(x, y, z, \omega) d y d S \\
\quad-\int_{S_{\mathrm{bs}}} \int_{-\infty}^{+\infty} t_{i j}^{\mathrm{Gn}}\left(x^{\prime}, 0, z^{\prime}, x, y-y^{\prime}, z, \omega\right) u_{\mathrm{s} j}(x, y, z, \omega) d y d S
\end{aligned}
$$

As the interface is invariant in the $y$-direction, the horizontal coordinate $y^{\prime}$ is transformed to the wavenumber domain:

$$
\begin{aligned}
\kappa \tilde{u}_{\mathrm{s} i}\left(x^{\prime}, k_{y}, z^{\prime}, \omega\right)= & \int_{-\infty}^{+\infty} \int_{S_{\mathrm{bs}}} \int_{-\infty}^{+\infty} \exp \left(+i k_{y} y^{\prime}\right) u_{i j}^{\mathrm{G}}\left(x^{\prime}, 0, z^{\prime}, x, y-y^{\prime}, z, \omega\right) t_{\mathrm{s} j}^{\mathrm{n}}(x, y, z, \omega) d y d S d y^{\prime} \\
& -\int_{-\infty}^{+\infty} \int_{S_{\mathrm{bs}}} \int_{-\infty}^{+\infty} \exp \left(+i k_{y} y^{\prime}\right) t_{i j}^{\mathrm{Gn}}\left(x^{\prime}, 0, z^{\prime}, x, y-y^{\prime}, z, \omega\right) u_{\mathrm{s} j}(x, y, z, \omega) d y d S d y^{\prime}
\end{aligned}
$$

Replacing $\exp \left(+i k_{y} y^{\prime}\right)$ by $\exp \left(-i k_{y}\left(y-y^{\prime}\right)\right) \exp \left(+i k_{y} y\right)$ and changing the order of integration, the following expression is obtained:

$$
\begin{array}{r}
\kappa \tilde{u}_{\mathrm{si}}\left(x^{\prime}, k_{y}, z^{\prime}, \omega\right)= \\
\int_{S_{\mathrm{bs}}} \int_{-\infty}^{+\infty}\left[\int_{-\infty}^{+\infty} \exp \left(-i k_{y}\left(y-y^{\prime}\right)\right) u_{i j}^{\mathrm{G}}\left(x^{\prime}, 0, z^{\prime}, x, y-y^{\prime}, z, \omega\right) d y^{\prime}\right] \exp \left(+i k_{y} y\right) t_{\mathrm{s} j}(x, y, z, \omega) d y d S \\
-\int_{S_{\mathrm{bs}}} \int_{-\infty}^{+\infty}\left[\int_{-\infty}^{+\infty} \exp \left(-i k_{y}\left(y-y^{\prime}\right)\right) t_{i j}^{\mathrm{Gn}}\left(x^{\prime}, 0, z^{\prime}, x, y-y^{\prime}, z, \omega\right) d y^{\prime}\right] \\
\times \exp \left(+i k_{y} y\right) u_{\mathrm{s} j}(x, y, z, \omega) d y d S
\end{array}
$$

The bracketed terms in equation (28) are identified as the Fourier transform of the Green's displacement and tractions, respectively:

$$
\begin{aligned}
\kappa \tilde{u}_{\mathrm{s} i}\left(x^{\prime}, k_{y}, z^{\prime}, \omega\right)=\int_{S_{\mathrm{bs}}} \tilde{u}_{i j}^{\mathrm{G}}\left(x^{\prime}, 0, z^{\prime}, x,-k_{y}, z, \omega\right)\left[\int_{-\infty}^{+\infty} \exp \left(+i k_{y} y\right) t_{\mathrm{s} j}^{\mathbf{n}}(x, y, z, \omega) d y\right] d S \\
\quad-\int_{S_{\mathrm{bs}}} \tilde{t}_{i j}^{\mathrm{Gn}}\left(x^{\prime}, 0, z^{\prime}, x,-k_{y}, z, \omega\right)\left[\int_{-\infty}^{+\infty} \exp \left(+i k_{y} y\right) u_{\mathrm{s} j}(x, y, z, \omega) d y\right] d S
\end{aligned}
$$

Subsequently, the bracketed terms in equation (29) are identified as the Fourier transforms of the displacements and tractions, respectively:

$$
\begin{aligned}
\kappa \tilde{u}_{\mathrm{si}}\left(x^{\prime}, k_{y}, z^{\prime}, \omega\right)=\int_{S_{\mathrm{bs}}} \tilde{u}_{i j}^{\mathrm{G}}\left(x^{\prime}, 0, z^{\prime}, x,-k_{y}, z, \omega\right) \tilde{t}_{\mathrm{s} j}^{\mathrm{n}}\left(x, k_{y}, z, \omega\right) d S \\
\quad-\int_{S_{\mathrm{bs}}} \tilde{t}_{i j}^{\mathrm{Gn}}\left(x^{\prime}, 0, z^{\prime}, x,-k_{y}, z, \omega\right) \tilde{u}_{\mathrm{s} j}\left(x, k_{y}, z, \omega\right) d S
\end{aligned}
$$


Equation (30) is the wavenumber domain integral representation theorem and agrees with the results presented by Sheng et al. [31]. Equation (30) can be used to compute the radiated wavefield in the soil for given displacements and tractions on the interface $S_{\mathrm{bs}}$. Equation (30) cannot be used, however, for the solution of the soil-structure interaction problem as it is not valid for source points $\left\{x^{\prime}, 0, z^{\prime}\right\}^{\mathrm{T}}$ located on the interface $S_{\mathrm{bs}}$. Therefore, a regularized boundary integral equation that allows for the solution of the displacements and tractions on the soil-structure interface is proposed in the next subsection.

\subsection{Regularization procedure}

Following a classical approach, the regularization of the boundary integral representation (30) results in Somigliana's identity that involves Cauchy principal value integrals of the singular fundamental tractions. This procedure is followed by Sheng et al. [31], who evaluate the Cauchy principal value integrals analytically. Alternatively, a regularization procedure $[5,7,28]$ is proposed in the present paper that avoids singular integration. This global regularization of the boundary integral equation is based on the fact that the singularity of the static and dynamic fundamental solutions at the source point correspond.

Since the rigid body identity only applies for bounded domains [5], it is elaborated for an auxiliary bounded domain $\Omega_{\mathrm{s}}^{\text {int }}$ that is enclosed by the boundary $\Sigma_{\mathrm{bs}}$ (figure 3 ). For an arbitrary rigid body translation

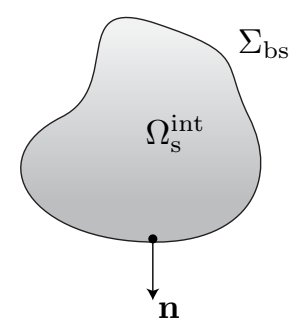

(a)

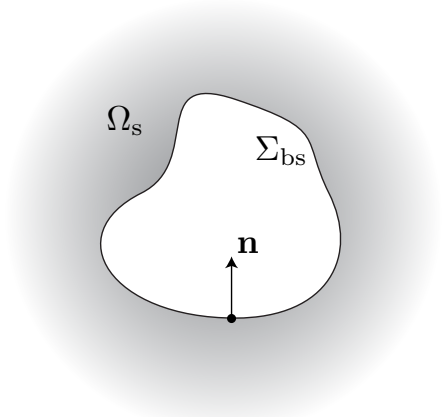

(b)

Figure 3: Definition of the auxiliary bounded domain $\Omega_{\mathrm{s}}^{\text {int }}$ enclosed by the boundary $\Sigma_{\mathrm{bs}}$ of $\Omega_{\mathrm{s}}$.

$u_{i}^{\text {rig }}$, the stress tensor is zero throughout the volume $\Omega_{\mathrm{s}}^{\text {int }}$. Application of the $3 \mathrm{D}$ integral representation theorem (24) results in the following rigid body identity [5]:

$$
\kappa u_{i}^{\mathrm{rig}}+u_{j}^{\mathrm{rig}} \int_{\Sigma_{\mathrm{bs}}} t_{i j}^{\mathrm{Gn}}\left(x^{\prime}, y^{\prime}, z^{\prime}, x, y, z, \omega=0\right) d \Gamma=0
$$

The longitudinal invariance is exploited, rewriting the surface integral in equation (31) as an integral over the interface $S_{\mathrm{bs}}$ and the longitudinal coordinate $y$. Furthermore, the source of the Green's function is shifted to the plane $y=0$ :

$$
\kappa u_{i}^{\mathrm{rig}}+u_{j}^{\mathrm{rig}} \int_{S_{\mathrm{bs}}} \int_{-\infty}^{+\infty} t_{i j}^{\mathrm{Gn}}\left(x^{\prime}, 0, z^{\prime}, x, y-y^{\prime}, z, \omega=0\right) d y d S=0
$$

The coordinate $y^{\prime}$ is transformed to the wavenumber domain:

$$
\kappa u_{i}^{\mathrm{rig}} \delta\left(k_{y}\right)+u_{j}^{\mathrm{rig}} \int_{-\infty}^{+\infty} \int_{S_{\mathrm{bs}}} \int_{-\infty}^{+\infty} \exp \left(+i k_{y} y^{\prime}\right) t_{i j}^{\mathrm{Gn}}\left(x^{\prime}, 0, z^{\prime}, x, y-y^{\prime}, z, \omega=0\right) d y d S d y^{\prime}=0
$$

Replacing $\exp \left(+i k_{y} y^{\prime}\right)$ by $\exp \left(-i k_{y}\left(y-y^{\prime}\right)\right) \exp \left(+i k_{y} y\right)$ and changing the order of integration, the follow- 
ing expression is obtained:

$$
\begin{aligned}
& \kappa u_{i}^{\mathrm{rig}} \delta\left(k_{y}\right)+u_{j}^{\mathrm{rig}} \\
& \times \int_{-\infty}^{+\infty} \int_{S_{\mathrm{bs}}}\left[\int_{-\infty}^{+\infty} \exp \left(-i k_{y}\left(y-y^{\prime}\right)\right) t_{i j}^{\mathrm{Gn}}\left(x^{\prime}, 0, z^{\prime}, x, y-y^{\prime}, z, \omega=0\right) d y^{\prime}\right] d S \exp \left(+i k_{y} y\right) d y=0
\end{aligned}
$$

The bracketed term in equation (34) is identified as the Fourier transform of the static Green's traction evaluated at $-k_{y}$ :

$$
\kappa u_{i}^{\mathrm{rig}} \delta\left(k_{y}\right)+u_{j}^{\mathrm{rig}} \int_{S_{\mathrm{bs}}} \tilde{t}_{i j}^{\mathrm{Gn}}\left(x^{\prime}, 0, z^{\prime}, x,-k_{y}, z, \omega=0\right) d S\left[\int_{-\infty}^{+\infty} \exp \left(+i k_{y} y^{\prime}\right) d y^{\prime}\right]=0
$$

Similarly, the bracketed integral in equation (35) is equal to the Dirac function $\delta\left(k_{y}\right)$ :

$$
\left[\kappa u_{i}^{\mathrm{rig}}+u_{j}^{\mathrm{rig}} \int_{S_{\mathrm{bs}}} \tilde{t}_{i j}^{\mathrm{Gn}}\left(x^{\prime}, 0, z^{\prime}, x,-k_{y}, z, \omega=0\right) d S\right] \delta\left(k_{y}\right)=0
$$

The presence of the Dirac function $\delta\left(k_{y}\right)$ implies that the bracketed term should only be zero at the wavenumber $k_{y}=0$. This corresponds to the fact that a rigid body translation of a longitudinally invariant body is entirely two-dimensional. Equation (36) therefore reduces to:

$$
\kappa u_{i}^{\mathrm{rig}}+u_{j}^{\mathrm{rig}} \int_{S_{\mathrm{bs}}} \tilde{t}_{i j}^{\mathrm{Gn}}\left(x^{\prime}, 0, z^{\prime}, x, k_{y}=0, z, \omega=0\right) d S=0
$$

If the rigid body translation $u_{i}^{\text {rig }}$ is chosen to be equal to the displacement $\tilde{u}_{\mathrm{s} i}\left(x^{\prime}, k_{y}, z^{\prime}, \omega\right)$, the following identity is obtained:

$$
\kappa \tilde{u}_{\mathrm{s} i}\left(x^{\prime}, k_{y}, z^{\prime}, \omega\right)+\tilde{u}_{\mathrm{s} j}\left(x^{\prime}, k_{y}, z^{\prime}, \omega\right) \int_{S_{\mathrm{bs}}} \tilde{t}_{i j}^{\mathrm{Gn}}\left(x^{\prime}, 0, z^{\prime}, x, k_{y}=0, z, \omega=0\right) d S=0
$$

The rigid body identity (38) is subtracted from the integral representation (30) in order to obtain a regularized boundary integral equation. As the integral representation (30) is only valid for points not located on the soil-structure interface $S_{\mathrm{bs}}$, a limiting procedure is followed. The procedure is similar to the regularization in the two-dimensional case [5], and yields the following regularized displacement integral equation for an unbounded domain:

$$
\begin{aligned}
& \tilde{u}_{\mathrm{s} i}\left(x^{\prime}, k_{y}, z^{\prime}, \omega\right)-\int_{S_{\mathrm{bs}}} \tilde{u}_{i j}^{\mathrm{G}}\left(x^{\prime}, 0, z^{\prime}, x,-k_{y}, z, \omega\right) \tilde{t}_{\mathrm{s} j}^{\mathbf{n}}\left(x, k_{y}, z, \omega\right) d S \\
&+\int_{S_{\mathrm{bs}}}\left[\tilde{t}_{i j}^{\mathrm{Gn}}\left(x^{\prime}, 0, z^{\prime}, x,-k_{y}, z, \omega\right) \tilde{u}_{\mathrm{s} j}\left(x, k_{y}, z, \omega\right)\right. \\
&\left.\quad-\tilde{t}_{i j}^{\mathrm{Gn}}\left(x^{\prime}, 0, z^{\prime}, x, k_{y}=0, z, \omega=0\right) \tilde{u}_{\mathrm{s} j}\left(x^{\prime}, k_{y}, z^{\prime}, \omega\right)\right] d S=0
\end{aligned}
$$

The strong singularity of the traction integral has been successfully removed, as the singularity of the $2.5 \mathrm{D}$ dynamic Green's traction $\tilde{t}_{i j}^{\mathrm{Gn}}\left(x^{\prime}, 0, z^{\prime}, x,-k_{y}, z, \omega\right)$ corresponds to the singularity of the two-dimensional static Green's traction $\tilde{t}_{i j}^{\mathrm{Gn}}\left(x^{\prime}, 0, z^{\prime}, x, k_{y}=0, z, \omega=0\right)$ when the receiver location $\{x, z\}^{\mathrm{T}}$ approaches the source location $\left\{x^{\prime}, z^{\prime}\right\}^{\mathrm{T}}[35]$. In the case of a bounded domain, a similar regularized displacement integral equation can be derived, where the integral-free term $\tilde{u}_{\mathrm{s} i}\left(x^{\prime}, k_{y}, z^{\prime}, \omega\right)$ in equation (39) vanishes.

\subsection{Boundary element discretization}

The regularized 2.5D boundary integral equation (39) is subsequently discretized with two-dimensional boundary elements. The displacement vector on the soil-structure interface $S_{\mathrm{bs}}$ is discretized as:

$$
\tilde{\mathbf{u}}_{\mathrm{s}}\left(x, k_{y}, z, \omega\right)=\mathbf{N}_{\mathrm{s}}(x, z) \tilde{\mathbf{u}}_{\mathrm{s}}\left(k_{y}, \omega\right)
$$


where the vector $\underline{\mathbf{u}}_{\mathrm{s}}\left(k_{y}, \omega\right)$ collects the boundary element displacement degrees of freedom and $\mathbf{N}_{\mathrm{s}}(x, z)$ are the two-dimensional boundary element interpolation functions defined on the soil-structure interface $S_{\mathrm{bs}}$. Similarly, the traction vector is discretized as:

$$
\tilde{\mathbf{t}}_{\mathrm{s}}^{\mathbf{n}}\left(x, k_{y}, z, \omega\right)=\mathbf{N}_{\mathrm{s}}(x, z) \tilde{\mathbf{t}}_{\mathrm{s}}\left(k_{y}, \omega\right)
$$

where the vector $\tilde{\mathbf{t}}_{\mathrm{s}}\left(k_{y}, \omega\right)$ collects the boundary element traction degrees of freedom.

The displacements and tractions on the interface $S_{\mathrm{bs}}$ are discretized by means of the same interpolation functions $\mathbf{N}_{\mathrm{s}}(x, z)$. Although it is possible to use different interpolation functions, this is a convenient choice as it results in a square system of equations. The interpolation nodes are commonly chosen at the center of the boundary elements and a constant interpolation is used for both displacements and tractions. An alternative is the isoparametric approach where the interpolation nodes correspond to the nodes of the boundary element mesh. These alternatives are referred to as element and nodal collocation, respectively [5]. A nodal collocation is followed in the present paper, as it allows for a straightforward coupling of the finite element and boundary element equations, as will be elaborated in section 4 .

The boundary element discretizations (40) and (41) are introduced in the regularized boundary integral equation (39). A point collocation method results in the following boundary element system of equations:

$$
\left[\tilde{\mathbf{T}}\left(k_{y}, \omega\right)+\mathbf{I}\right] \tilde{\mathbf{u}}_{\mathbf{s}}\left(k_{y}, \omega\right)=\tilde{\mathbf{U}}\left(k_{y}, \omega\right) \tilde{\mathbf{t}}_{\mathbf{s}}\left(k_{y}, \omega\right)
$$

where $\tilde{\mathbf{U}}\left(k_{y}, \omega\right)$ and $\tilde{\mathbf{T}}\left(k_{y}, \omega\right)$ are fully populated unsymmetric boundary element system matrices. The unit matrix $\mathbf{I}$ corresponds to the integral-free term in equation (39) and is not present in the case of a bounded medium.

After the solution of a $2.5 \mathrm{D}$ boundary value problem by means of equation (42), the radiated wavefield is computed by means of the integral representation (30). Introducing the boundary element discretizations (40) and (41) into equation (30) allows to compute the radiated wavefield as:

$$
\underline{\tilde{\mathbf{u}}}_{\mathrm{r}}\left(k_{y}, \omega\right)=\tilde{\mathbf{U}}_{\mathrm{r}}\left(k_{y}, \omega\right) \tilde{\mathbf{t}}_{\mathrm{s}}\left(k_{y}, \omega\right)-\tilde{\mathbf{T}}_{\mathrm{r}}\left(k_{y}, \omega\right) \underline{\tilde{\mathbf{u}}}_{\mathrm{s}}\left(k_{y}, \omega\right)
$$

where the vector $\underline{\underline{\mathbf{u}}}_{\mathrm{r}}\left(k_{y}, \omega\right)$ collects the displacement components at $n_{\mathrm{r}}$ receiver locations.

\subsection{Validation of the boundary element method}

The boundary element method is validated by means of the benchmark example of a cylindrical cavity in a full space (figure 4) $[11,12]$. The cavity has a radius $r_{0}=1 \mathrm{~m}$ and the full space has a shear wave velocity $C_{\mathrm{s}}=150 \mathrm{~m} / \mathrm{s}$, a dilatational wave velocity $C_{\mathrm{p}}=300 \mathrm{~m} / \mathrm{s}$, a density $\rho=1800 \mathrm{~kg} / \mathrm{m}^{3}$, and a material damping ratio $\beta_{\mathrm{s}}=\beta_{\mathrm{p}}=0.05$ in both deviatoric and volumetric deformation. The cavity is loaded by a pressure $\tilde{p}\left(k_{y}, \omega\right)=1$ that is harmonic with respect to the longitudinal coordinate $y$ with a wavelength $2 \pi / k_{y}$ (figure 4). This loading results in a radial displacement $\tilde{u}_{r}\left(r, k_{y}, \omega\right)$ in the full space that is axisymmetric around the $y$-axis and varies harmonically with respect to the coordinate $y$ with the same wavelength $2 \pi / k_{y}$ as the load. Correspondingly, the wavefield around the cavity is characterized by both dilatational and shear waves.

An analytical reference solution for the cavity problem has been derived by Forrest and Hunt $[11,12]$ by considering the equilibrium equation of a thick-walled cylindrical tube with an internal radius $r_{0}$ and a limiting large external radius. The solution is expressed in terms of modified Bessel functions of the second kind and reduces to the two-dimensional reference solution of Eringen and Suhubi [10] for $k_{y}=0$, in which case the solution only depends on the dilatational wave velocity $C_{\mathrm{p}}$. For $k_{y} \neq 0$, the solution also depends on the shear wave velocity $C_{\mathrm{s}}$.

Two 2.5D boundary element meshes with 10 and 50 equal sized linear elements over the circumference of the cavity, respectively, are used. The analytical 2.5D full space Green's functions [35] are integrated using 6 integration points per element.

Figure 5 shows the radial displacement $\tilde{u}_{r}\left(r=r_{0}, k_{y}, \omega\right)$ at the wall of the cavity for a dimensionless wavenumber $\bar{k}_{y}=k_{y} \omega / C_{\mathrm{s}}=0, \bar{k}_{y}=0.5$, and $\bar{k}_{y}=1$. The results obtained with the $2.5 \mathrm{D}$ boundary element 


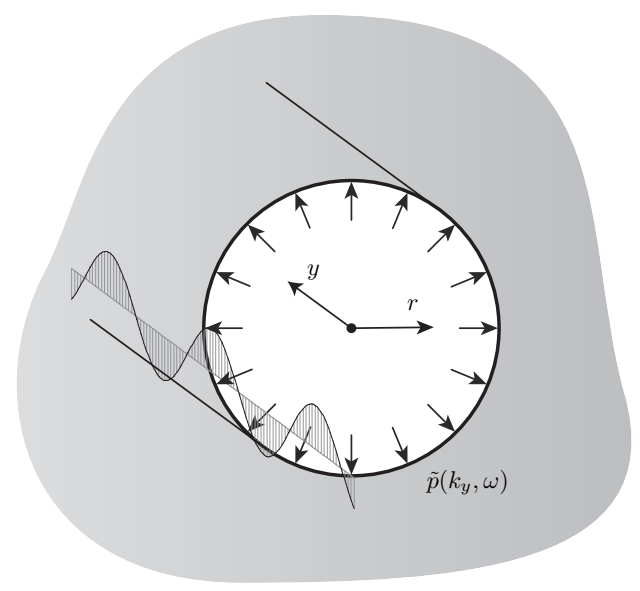

Figure 4: Cylindrical cavity.

model are in good agreement with the analytical solution and converge for an increasing number of boundary elements. This validates the 2.5D regularized boundary integral equation (39) and its implementation.

Similarly, the radial displacement $\tilde{u}_{r}\left(r, k_{y}, \omega\right)$ at a distance $r=10 \mathrm{~m}$ of the center of the cavity (figure $6)$ are in good agreement with the analytical solution, validating also equation (43).
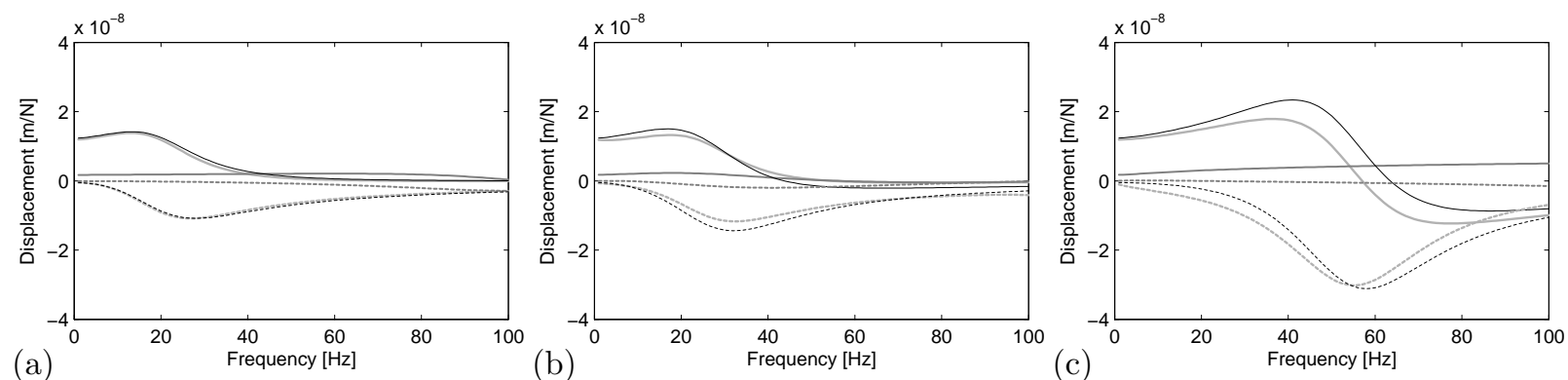

Figure 5: Real (solid line) and imaginary (dashed line) part of the radial displacement $\tilde{u}_{r}\left(r=r_{0}, k_{y}, \omega\right)$ on the wall of the cavity with radius $r_{0}=1 \mathrm{~m}$ subjected to a spatially harmonic internal pressure $\tilde{p}\left(k_{y}, \omega\right)$ at a dimensionless wavenumber (a) $\bar{k}_{y}=0$, (b) $\bar{k}_{y}=0.5$, and (c) $\bar{k}_{y}=1$. The results obtained with the $2.5 \mathrm{D}$ boundary element model with 10 (light gray lines) and 50 (dark gray lines) boundary elements around the circumference are compared with the analytical reference solution (black lines).

\subsection{Evaluation of the Green's functions of a layered halfspace}

The computation of the boundary element system matrices $\tilde{\mathbf{U}}\left(k_{y}, \omega\right)$ and $\tilde{\mathbf{T}}\left(k_{y}, \omega\right)$ in equation (42) requires the wavenumber-frequency domain Green's displacements $\tilde{u}_{i j}^{\mathrm{G}}$ and tractions $\tilde{t}_{i j}^{\mathrm{Gn}}$. Commonly, the $2.5 \mathrm{D}$ homogeneous full space solution $[32,35]$ is used. If the geometry involves a layered halfspace, the use of the homogeneous full space solution has the disadvantage that the traction free surface and the layer interfaces of the halfspace have to be discretized with boundary elements. Meshing of the infinite surface and interfaces requires mesh truncation, at which spurious reflections may occur. These disadvantages are avoided: in this paper, the Green's functions of a layered halfspace are used which does not require meshing of the infinite surface and interfaces. The fundamental solutions are computed by means of the direct stiffness method [20, 21] using the MATLAB toolbox EDT 2.1 [29]. As the traction free surface of the halfspace and the layer interfaces are included in these fundamental solutions, only the interface $\Sigma_{\mathrm{bs}}$ between the structure and the layered halfspace is discretized.

In every boundary element collocation point, a source $\left\{x^{\prime}, 0, z^{\prime}\right\}^{\mathrm{T}}$ is considered. For every source position, the Green's displacements and tractions are evaluated at all boundary element integration points. The 


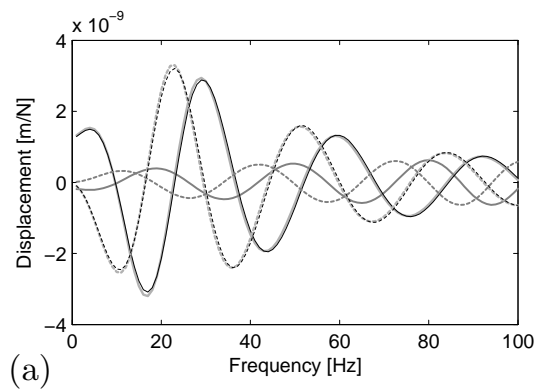

(a)

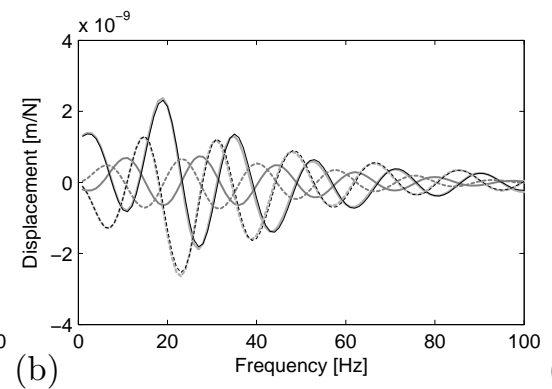

(b)

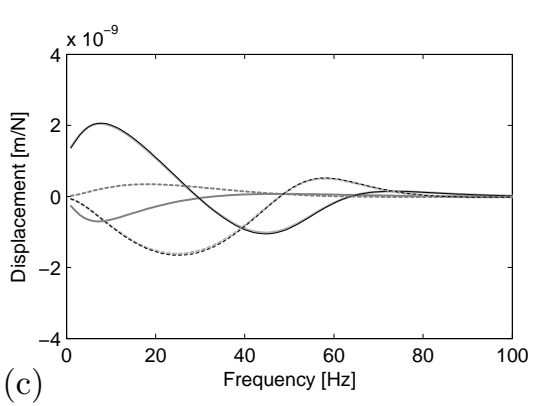

(c)

Figure 6: Real (solid line) and imaginary (dashed line) part of the radial displacement $\tilde{u}_{r}\left(r, k_{y}, \omega\right)$ at a distance $r=10 \mathrm{~m}$ of the center of the cavity with radius $r_{0}=1 \mathrm{~m}$ subjected to a spatially harmonic internal pressure $\tilde{p}\left(k_{y}, \omega\right)$ at a dimensionless wavenumber (a) $\bar{k}_{y}=0$, (b) $\bar{k}_{y}=0.5$, and (c) $\bar{k}_{y}=1$. The results obtained with the $2.5 \mathrm{D}$ boundary element model with 10 (light gray lines) and 50 (dark gray lines) boundary elements around the circumference are compared to the analytical reference solution (black lines).

boundary element collocation point corresponds to the nodes of the mesh in the case of nodal collocation or to the element center in the case of element collocation [5]. The boundary element integration points are based on a Gaussian integration over the element (figure 7). In order to avoid the evaluation of the Green's functions for every combination of collocation and integration points, the Green's functions are evaluated on a grid. During the boundary element integration, the Green's functions are evaluated at the boundary element integration points by interpolation on this grid.

As the soil is invariant in the horizontal direction, the Green's functions only depend on the relative horizontal position of source and receiver. Therefore, the source position is placed at the depth of every collocation point along the line $\left\{x^{\prime}=0, z^{\prime}\right\}^{\mathrm{T}}$ (figure 7).

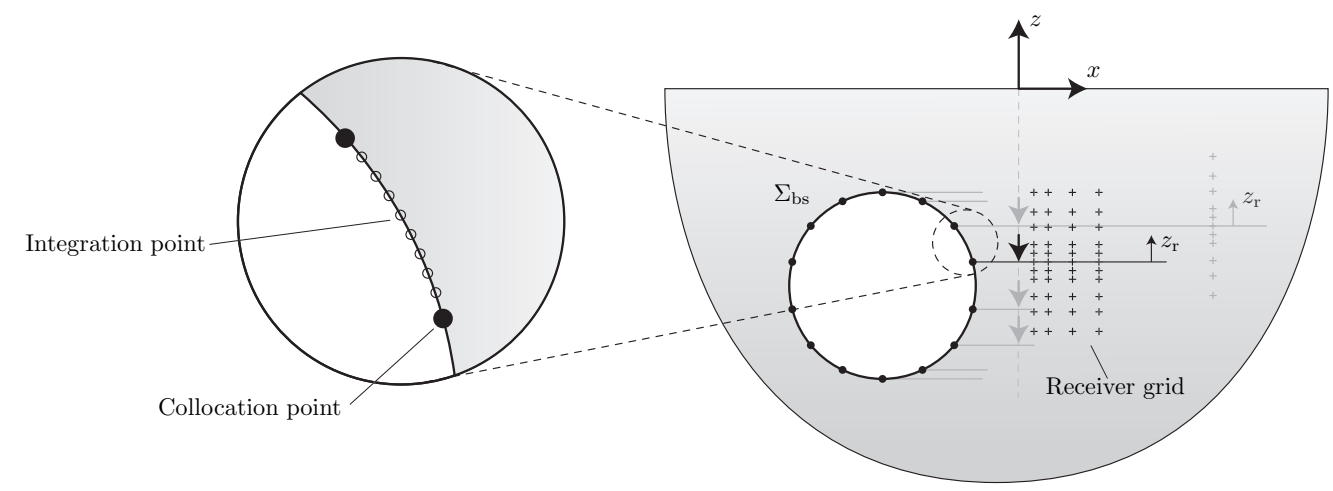

Figure 7: The evaluation of the Green's function at relative receiver depths.

The Green's displacements and tractions exhibit a singular behaviour around the source $z^{\prime}$. In order to properly sample the Green's functions around the source, the receivers of the grid are concentrated around the source point. Therefore, the receiver grid is defined in terms of the relative depth $z_{\mathrm{r}}$ of the receiver with respect to the vertical source position $z^{\prime}$. The relative receiver grid is the same for every source location (figure 7). For the boundary element integration, the Green's displacements and tractions at the boundary element integration points are interpolated from this grid.

\section{Finite element - boundary element coupling}

The boundary element system of equations (42) allows to compute the dynamic soil stiffness matrix $\tilde{\mathbf{K}}_{\mathrm{bb}}^{\mathrm{s}}\left(k_{y}, \omega\right)$ in equation $(23)$. The finite element degrees of freedom $\underline{\mathbf{u}}_{\mathrm{b}}$ are divided into internal degrees 
of freedom $\underline{\mathbf{u}}_{\mathrm{b}_{1}}$ and degrees of freedom $\underline{\mathbf{u}}_{\mathrm{b}_{2}}$ on the soil-structure interface (figure 1). This allows to write equation (23) as:

$$
\begin{aligned}
& \left(-\omega^{2}\left[\begin{array}{ll}
\mathbf{M}_{\mathrm{b}_{1} \mathrm{~b}_{1}} & \mathbf{M}_{\mathrm{b}_{1} \mathrm{~b}_{2}} \\
\mathbf{M}_{\mathrm{b}_{2} \mathrm{~b}_{1}} & \mathbf{M}_{\mathrm{b}_{2} \mathrm{~b}_{2}}
\end{array}\right]+\left[\begin{array}{ll}
\mathbf{K}_{\mathrm{b}_{1} \mathrm{~b}_{1}}^{0} & \mathbf{K}_{\mathrm{b}_{1} \mathrm{~b}_{2}}^{0} \\
\mathbf{K}_{\mathrm{b}_{2} \mathrm{~b}_{1}}^{0} & \mathbf{K}_{\mathrm{b}_{2} \mathrm{~b}_{2}}^{0}
\end{array}\right]-i k_{y}\left[\begin{array}{ll}
\mathbf{K}_{\mathrm{b}_{1} \mathrm{~b}_{1}}^{1} & \mathbf{K}_{\mathrm{b}_{1} \mathrm{~b}_{2}}^{1} \\
\mathbf{K}_{\mathrm{b}_{2} \mathrm{~b}_{1}}^{1} & \mathbf{K}_{\mathrm{b}_{2} \mathrm{~b}_{2}}^{1}
\end{array}\right]\right. \\
& -k_{y}^{2}\left[\begin{array}{ll}
\mathbf{K}_{\mathrm{b}_{1} \mathrm{~b}_{1}}^{2} & \mathbf{K}_{\mathrm{b}_{1} \mathrm{~b}_{2}}^{2} \\
\mathbf{K}_{\mathrm{b}_{2} \mathrm{~b}_{1}}^{2} & \mathbf{K}_{\mathrm{b}_{2} \mathrm{~b}_{2}}^{2}
\end{array}\right]-i k_{y}^{3}\left[\begin{array}{ll}
\mathbf{K}_{\mathrm{b}_{1} \mathrm{~b}_{1}}^{3} & \mathbf{K}_{\mathrm{b}_{1} \mathrm{~b}_{2}}^{3} \\
\mathbf{K}_{\mathrm{b}_{2} \mathrm{~b}_{1}}^{3} & \mathbf{K}_{\mathrm{b}_{2} \mathrm{~b}_{2}}^{3}
\end{array}\right] \\
& \left.+k_{y}^{4}\left[\begin{array}{ll}
\mathbf{K}_{\mathrm{b}_{1} \mathrm{~b}_{1}}^{4} & \mathbf{K}_{\mathrm{b}_{1} \mathrm{~b}_{2}}^{4} \\
\mathbf{K}_{\mathrm{b}_{2} \mathrm{~b}_{1}}^{4} & \mathbf{K}_{\mathrm{b}_{2} \mathrm{~b}_{2}}^{4}
\end{array}\right]+\left[\begin{array}{cc}
0 & 0 \\
0 & \tilde{\mathbf{K}}_{\mathrm{b}_{2} \mathrm{~b}_{2}}^{\mathrm{s}}\left(k_{y}, \omega\right)
\end{array}\right]\right)\left[\begin{array}{c}
\tilde{\mathbf{u}}_{\mathrm{b}_{1}}\left(k_{y}, \omega\right) \\
\tilde{\tilde{\mathbf{u}}}_{\mathrm{b}_{2}}\left(k_{y}, \omega\right)
\end{array}\right]=\left[\begin{array}{c}
0 \\
\tilde{\tilde{\mathbf{f}}}_{\mathrm{b}_{2}}\left(k_{y}, \omega\right)
\end{array}\right]
\end{aligned}
$$

The dynamic soil stiffness matrix $\tilde{\mathbf{K}}_{\mathrm{b}_{2} \mathrm{~b}_{2}}^{\mathrm{s}}\left(k_{y}, \omega\right)$ is written as:

$$
\tilde{\mathbf{K}}_{\mathrm{b}_{2} \mathrm{~b}_{2}}^{\mathrm{s}}\left(k_{y}, \omega\right)=\int_{S_{\mathrm{bs}}} \mathbf{N}_{\mathrm{b}_{2}}^{\mathrm{T}} \tilde{\mathbf{t}}_{\mathrm{s}}^{\mathbf{n}_{\mathrm{s}}}\left(\mathbf{N}_{\mathrm{b}_{2}}\right)\left(x, k_{y}, z, \omega\right) d S
$$

The boundary element mesh is chosen to match the finite element mesh on the soil-structure interface $S_{\text {bs }}$. As a result, the boundary element interpolation functions $\mathbf{N}_{\mathrm{s}}(x, z)$ correspond to the finite element shape functions $\mathbf{N}_{\mathrm{b}_{2}}(x, z)$ on the soil-structure interface. This allows to introduce the boundary element traction discretization in equation (45):

$$
\tilde{\mathbf{K}}_{\mathrm{b}_{2} \mathrm{~b}_{2}}^{\mathrm{s}}\left(k_{y}, \omega\right)=\int_{S_{\mathrm{bs}}} \mathbf{N}_{\mathrm{b}_{2}}^{\mathrm{T}} \mathbf{N}_{\mathrm{b}_{2}} d S \quad \tilde{\mathbf{t}}_{\mathrm{s}}\left(\mathbf{N}_{\mathrm{b}_{2}}\right)\left(k_{y}, \omega\right)
$$

The integral $\mathbf{T}_{\mathrm{q}}=\int_{S_{\mathrm{bs}}} \mathbf{N}_{\mathrm{b}_{2}}^{\mathrm{T}} \mathbf{N}_{\mathrm{b}_{2}} d S$ in equation (45) is independent of wavenumber and frequency, which allows to write the dynamic soil stiffness matrix $\tilde{\mathbf{K}}_{\mathrm{b}_{2} \mathrm{~b}_{2}}^{\mathrm{s}}\left(k_{y}, \omega\right)$ as:

$$
\tilde{\mathbf{K}}_{\mathrm{b}_{2} \mathrm{~b}_{2}}^{\mathrm{s}}\left(k_{y}, \omega\right)=\mathbf{T}_{\mathrm{q}} \tilde{\mathbf{t}}_{\mathrm{s}}\left(\mathbf{N}_{\mathrm{b}_{2}}\right)\left(k_{y}, \omega\right)
$$

The tractions $\tilde{\mathbf{t}}_{\mathrm{s}}\left(\mathbf{N}_{\mathrm{b}_{2}}\right)\left(k_{y}, \omega\right)$ are found as the solution of the boundary element system of equations (42):

$$
\tilde{\mathbf{t}}_{\mathrm{s}}\left(\mathbf{N}_{\mathrm{b}_{2}}\right)\left(k_{y}, \omega\right)=\tilde{\mathbf{U}}^{-1}\left(k_{y}, \omega\right)\left(\tilde{\mathbf{T}}\left(k_{y}, \omega\right)+\mathbf{I}\right)
$$

Equation (48) is introduced in equation (47):

$$
\tilde{\mathbf{K}}_{\mathrm{b}_{2} \mathrm{~b}_{2}}^{\mathrm{s}}\left(k_{y}, \omega\right)=\mathbf{T}_{\mathrm{q}} \tilde{\mathbf{U}}^{-1}\left(k_{y}, \omega\right)\left(\tilde{\mathbf{T}}\left(k_{y}, \omega\right)+\mathbf{I}\right)
$$

which allows to compute the soil stiffness matrix $\tilde{\mathbf{K}}_{\mathrm{b}_{2} \mathrm{~b}_{2}}^{\mathrm{s}}\left(k_{y}, \omega\right)$ from the boundary element system matrices $\tilde{\mathbf{U}}^{-1}\left(k_{y}, \omega\right)$ and $\tilde{\mathbf{T}}\left(k_{y}, \omega\right)$.

\section{Applications}

\subsection{Road on a halfspace}

As a first example, a road on a halfspace is considered (figure 8). The halfspace has a shear wave velocity $C_{\mathrm{s}}=150 \mathrm{~m} / \mathrm{s}$, a dilatational wave velocity $C_{\mathrm{p}}=300 \mathrm{~m} / \mathrm{s}$, a density $\rho=1800 \mathrm{~kg} / \mathrm{m}^{3}$ and a material damping ratio $\beta_{\mathrm{s}}=\beta_{\mathrm{p}}=0.05$ in both deviatoric and volumetric deformation. The road consists of several layers which characteristics are summarized in table 1 . The road has a width of $4 \mathrm{~m}$ and is loaded by a vertical unit harmonic point load at the center of the road. The road is modelled with $402.5 \mathrm{D}$ shell elements of equal size. The soil is modelled with $2.5 \mathrm{D}$ boundary elements conforming with the finite element mesh.

The solution of the coupled FE-BE equation (44) results in the displacements of the road in the wavenumber-frequency domain. The wavenumber-frequency domain solution is subsequently transformed 


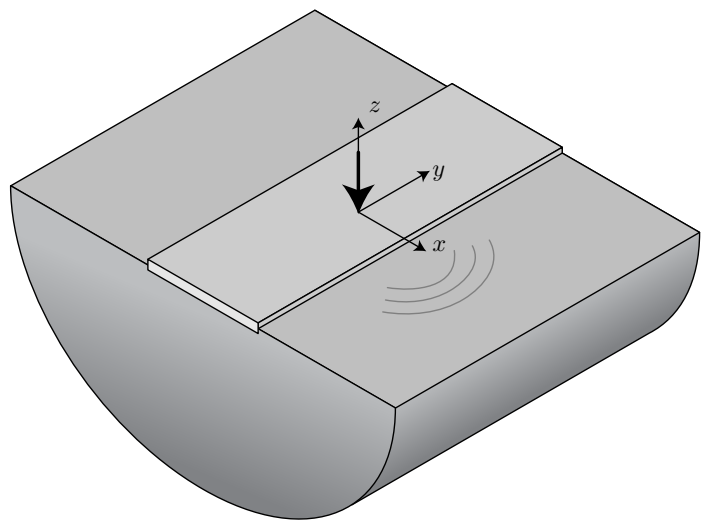

Figure 8: Road on a halfspace.

\begin{tabular}{cccccc}
\hline Layer & Type & $\begin{array}{c}d \\
{[\mathrm{~m}]}\end{array}$ & $\begin{array}{c}E \\
{[\mathrm{MPa}]}\end{array}$ & $\begin{array}{c}\nu \\
{[-]}\end{array}$ & $\begin{array}{c}\rho \\
{\left[\mathrm{kg} / \mathrm{m}^{3}\right]}\end{array}$ \\
\hline 1 & Asphalt & 0.15 & 9150 & $1 / 3$ & 2100 \\
2 & Crushed stone & 0.20 & 500 & $1 / 2$ & 2000 \\
3 & Crushed concrete & 0.25 & 200 & $1 / 2$ & 1800 \\
\hline
\end{tabular}

Table 1: The characteristics of the road.

to the spatial domain by means of an inverse Fast Fourier Transform (FFT) of the wavenumber $k_{y}$ to the coordinate $y$. The wavenumber sampling is specified in terms of the dimensionless wavenumber $\bar{k}_{y}=k_{y} C_{\mathrm{s}} / \omega$. As both the response of the road and the layered halfspace strongly decay for dimensionless wavenumbers larger than $\bar{k}_{y}=1[22,23]$, a maximum dimensionless wavenumber $\bar{k}_{y}=3$ is sufficient to accurately compute the displacements in the in the far field.

Nyquist's theorem states that the wavenumber step $\Delta k_{y}$ should be smaller than $2 \pi / y_{\max }$ where $y_{\max }$ is a distance where the solution is sufficiently attenuated. Specifying the distance $y_{\max }$ in terms of a number $n$ of shear wavelengths $\lambda_{\mathrm{s}}$, allows to determine the dimensionless wavenumber step as $\Delta \bar{k}_{y}=1 / n$. In the present analysis, $n=100$ wavelengths are considered, resulting in 300 samples from $\bar{k}_{y}=0$ to $\bar{k}_{y}=3$.

Figure 9a shows the real part of the vertical displacements on the road and on the surface of the halfspace at $10 \mathrm{~Hz}$. The wavelength of the Rayleigh waves in the soil is much larger than the width of the road. As a result, the wavefield is characterized by nearly cylindrical wave fronts. The results are compared with the results obtained with a model previously proposed by Lombaert [22] and Lombaert and Degrande [23] (figure $9 \mathrm{~b})$. In this model, the road is modelled as a beam with a rigid cross section where only vertical tractions on the interface between the road and the halfspace are considered, referred to as relaxed boundary conditions. In the frequency range up to $50 \mathrm{~Hz}$ considered for road traffic, the results between the road modelled with shell elements and the road with a rigid cross-section compare well.

Figure 10 compares the real and imaginary part of the vertical displacement in the point $\{10 \mathrm{~m}, 0,0\}^{\mathrm{T}}$ on the surface of the halfspace. The results obtained with both models correspond well, in particular at low frequencies.

In the case of a model of a railway track, for which higher frequency components are important, or in the case of a road with a large width, the assumption of a rigid cross-section for the soil-structure interface may no longer be valid. The present methodology allows investigating the validity of these assumptions made in existing models for railway traffic [25].

\subsection{Tunnel in a layered halfspace}

In the second example, the wavefield radiated by a concrete tunnel embedded in a layered halfspace due to a unit vertical harmonic point load at the tunnel invert is considered. The displacements are computed 


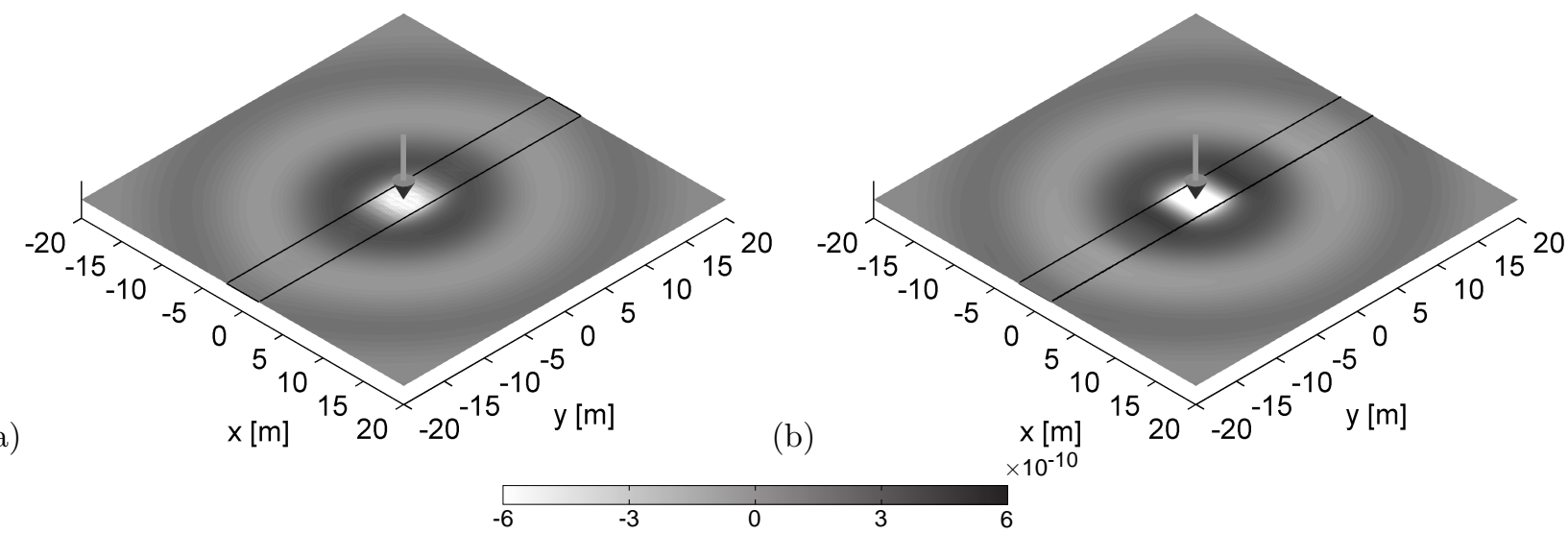

Figure 9: Real part of the vertical displacements on the road and on the surface of the halfspace for a unit vertical point load applied on the road with a width of $4 \mathrm{~m}$ at a frequency of $10 \mathrm{~Hz}$ The results are shown for (a) a model using $402.5 \mathrm{D}$ shell elements and (b) the model of Lombaert [22] and Lombaert and Degrande [23], modelling the road as a beam with rigid cross section.

(a)

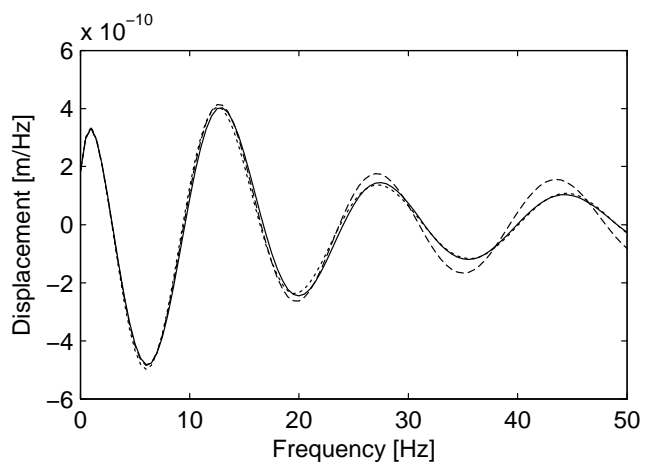

(b)

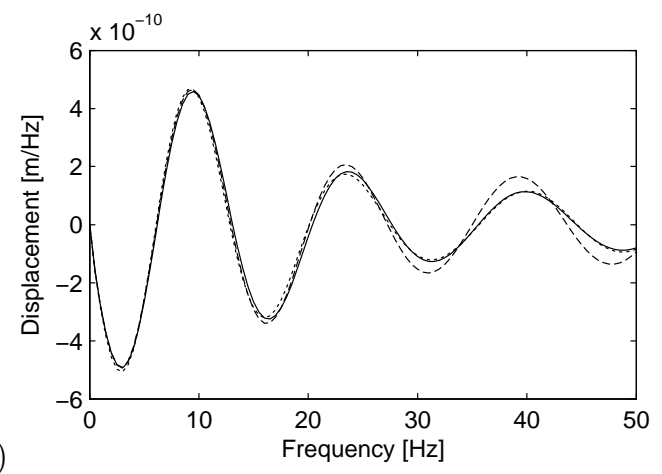

Figure 10: (a) Real and (b) imaginary part of the vertical displacement in the point $\{10 \mathrm{~m}, 0,0\}^{\mathrm{T}}$ on the surface of the halfspace for a unit vertical point load applied at the center the road. The results are shown for (a) the model using $402.5 \mathrm{D}$ shell elements and (b) the model of Lombaert [22] and Lombaert and Degrande [23], modelling the road as a beam with rigid cross section.

with the proposed methodology and compared with the results obtained with the analytical Pipe-in-Pipe (PiP) model [18].

The center of the tunnel is situated at a depth of $14 \mathrm{~m}$ below the free surface. The tunnel has an internal radius $r_{\mathrm{i}}=2.75 \mathrm{~m}$ and a wall thickness $t=0.25 \mathrm{~m}$ (Figure 11). The concrete has a Young's modulus $E=50000 \mathrm{MPa}$, a Poisson's ratio $\nu=0.30$, a density $\rho=2500 \mathrm{~kg} / \mathrm{m}^{3}$ and a hysteretic material damping ratio $\beta=0.03$.

The soil consists of layer with a thickness of $6 \mathrm{~m}$ on top of a homogeneous halfspace. The surface layer has a shear wave velocity $C_{\mathrm{s}}=275 \mathrm{~m} / \mathrm{s}$, a dilatational wave velocity $C_{\mathrm{p}}=1964 \mathrm{~m} / \mathrm{s}$, a density $\rho=1980 \mathrm{~m} / \mathrm{s}$ and a material damping ratio $\beta_{\mathrm{s}}=\beta_{\mathrm{p}}=0.04$ in both deviatoric and volumetric deformation. The halfspace has a shear wave velocity $C_{\mathrm{s}}=220 \mathrm{~m} / \mathrm{s}$, a dilatational wave velocity $C_{\mathrm{p}}=1571 \mathrm{~m} / \mathrm{s}$, a density $\rho=1980 \mathrm{~m} / \mathrm{s}$ and a material damping ratio $\beta_{\mathrm{s}}=\beta_{\mathrm{p}}=0.04$ in both deviatoric and volumetric deformation. The wave velocities of the soil layers correspond to a nearly-incompressible material, which is a reasonable assumption for fully saturated soils.

The response of the tunnel and the halfspace is computed using the 2.5D coupled FE-BE methodology. The tunnel is modelled with 36 equal-sized 2.5D shell elements around the circumference of the tunnel. The boundary element mesh matches the finite element mesh, which allows to compute the tunnel response by means of equation (45). 


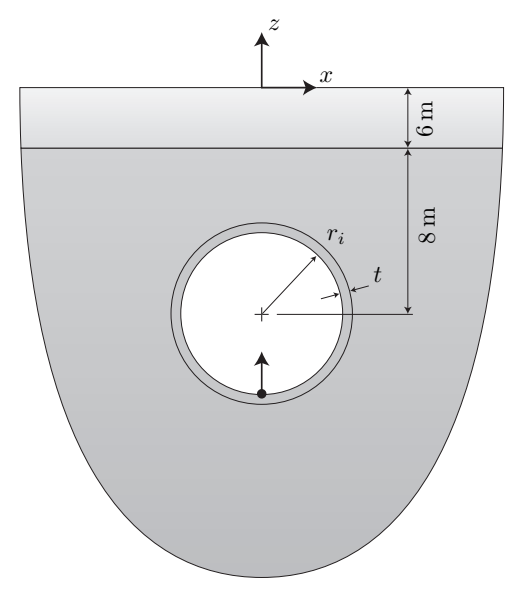

Figure 11: Cross section of the tunnel.

Figure 12 shows the vertical displacement at the surface of the layered halfspace due to a unit vertical point load at the tunnel invert at a frequency of $20 \mathrm{~Hz}$. Waves generated at the tunnel invert propagate through the soil and result in Rayleigh waves at the surface of the layered halfspace. The wavefronts on the surface of the halfspace are not cylindrical, which is a result of the dynamic interaction between the soil and the tunnel.

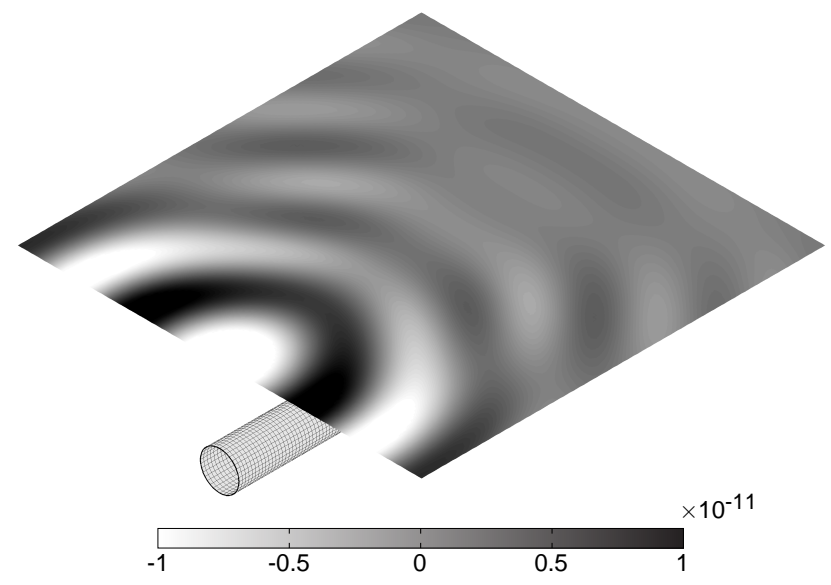

Figure 12: Real part of the vertical displacement at the surface of the layered halfspace due to a unit vertical point load at the tunnel invert at a frequency of $20 \mathrm{~Hz}$.

Figures $13 \mathrm{a}$ and $13 \mathrm{~b}$ show the vertical free-field displacement at the point with coordinates $\{10 \mathrm{~m}, 10 \mathrm{~m},-6 \mathrm{~m}\}^{\mathrm{T}}$ on the layer interface and at the point with coordinates $\{10 \mathrm{~m}, 10 \mathrm{~m}, 0 \mathrm{~m}\}^{\mathrm{T}}$ on the surface of the layered halfspace.

The results obtained with the presented 2.5D coupled FE-BE methodology are compared to the results obtained with the semi-analytical PiP model. In the PiP model, the tunnel-soil interaction is solved analytically, where the tunnel is assumed to be embedded in a homogeneous full space. The tunnel response is subsequently used to compute the displacements in the layered halfspace using the direct stiffness method, where the tunnel is replaced by a number of equivalent point sources in the layered halfspace [18]. A good agreement between both models is observed. The discrepancy between both models at higher frequencies is attributed to the limited wavenumber sampling in the $\mathrm{PiP}$ model for the computation of the free field response. 

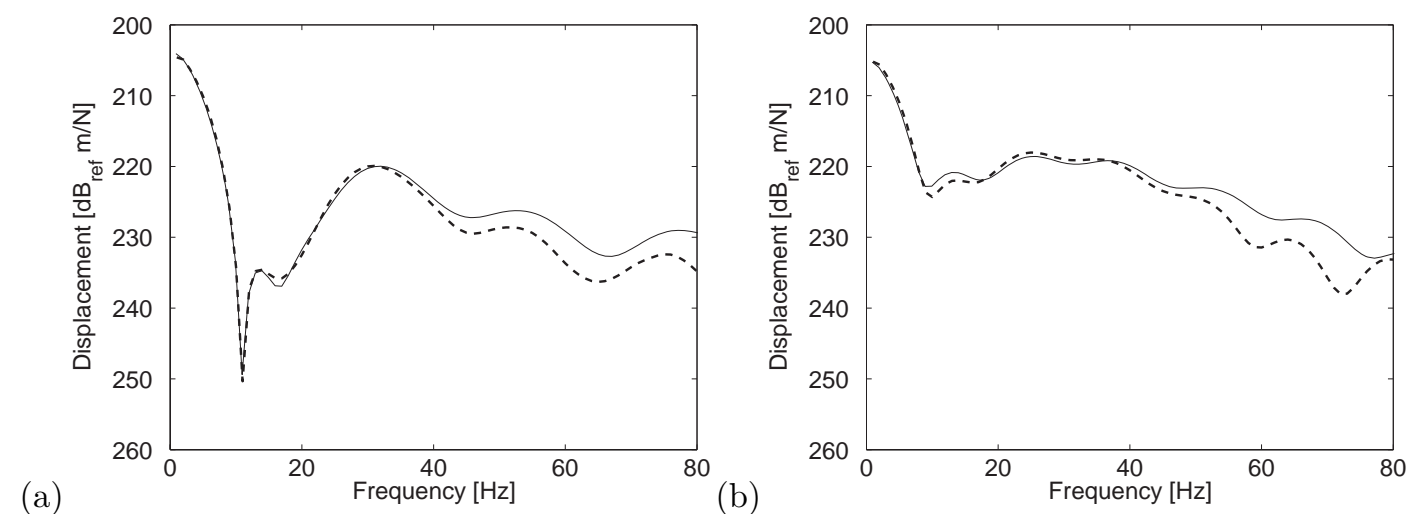

Figure 13: Modulus of the vertical displacement in (a) the point with coordinates $\{10 \mathrm{~m}, 10 \mathrm{~m},-6 \mathrm{~m}\}^{\mathrm{T}}$ and (b) at the point with coordinates $\{10 \mathrm{~m}, 10 \mathrm{~m}, 0 \mathrm{~m}\}^{\mathrm{T}}$. The results obtained with the presented methodology (dashed line) is compared with results obtained with the PiP model (solid line).

\subsection{Wave propagation along a dike}

In the third example, the wave propagation along an earth dam is studied. The aim of this analysis is to verify the assumptions made in seismic tomography on earth dams [19], where a Seismic Analysis of Surface Waves technique is used as a non-destructive technique to determine the dynamic soil characteristics of a dike from the dispersion of seismic surface waves [13].

The first step involves an in situ experiment where vibrations are generated at the dike surface using a falling weight, an instrumented impact hammer or a hydraulic shaker and measured with geophones or accelerometers up to a distance from the source of typically $50 \mathrm{~m}$. In the second step, an experimental dispersion curve is determined using the phase of the transfer functions between pairs of receivers. It is assumed that the response at sufficiently large distance from the source is dominated by dispersive surface waves. The experimental dispersion curve corresponds to the effective (dominant) wave velocity. An inverse problem is formulated as an optimization problem where the objective function is defined as the squared difference between the experimental and a computed theoretical dispersion curve.

The MASW method is commonly applied to sites with a flat free surface and the solution of the inverse problem is based on the assumption that the subgrade can be modelled as a layered elastic halfspace. When the MASW method is employed to determine the dynamic soil characteristics of dikes, the pertinent question is under what conditions the inverse problem can still be formulated based on the dispersion curve of a layered halfspace with a flat free surface where the elevated topography is not included.

To investigate the validity of this assumption, a soft earth dam with a steep slope on top of a homogeneous halfspace is considered in this example. The dam has a height $h=5 \mathrm{~m}$, a base width $w_{\mathrm{b}}=20 \mathrm{~m}$ and a top width $w_{\mathrm{t}}=2 \mathrm{~m}$. The dam consists of a soft soil with a shear wave velocity $C_{\mathrm{s}}=150 \mathrm{~m} / \mathrm{s}$, a dilatational wave velocity $C_{\mathrm{p}}=300 \mathrm{~m} / \mathrm{s}$, a density $\rho=2000 \mathrm{~kg} / \mathrm{m}^{3}$, and a material damping ratio $\beta_{\mathrm{s}}=\beta_{\mathrm{p}}=0.02$ in both deviatoric and volumetric deformation. The dam is founded on a homogeneous halfspace with a shear wave velocity $C_{s}=300 \mathrm{~m} / \mathrm{s}$, a dilatational wave velocity $C_{\mathrm{p}}=600 \mathrm{~m} / \mathrm{s}$, a density $\rho=2000 \mathrm{~kg} / \mathrm{m}^{3}$ and a material damping ratio $\beta_{\mathrm{s}}=\beta_{\mathrm{p}}=0.02$ in both deviatoric and volumetric deformation.

The 2.5D coupled FE-BE methodology is used to compute the response of the dike and the surrounding soil due to a unit vertical point load on top of the dike. The dike is modelled using $2.5 \mathrm{D}$ volume elements (figure 14) and the subgrade is modelled using $2.5 \mathrm{D}$ boundary element mesh that matches the finite element mesh on the dike-soil interace.

Figure 15 shows the real part of the vertical displacement of the dike and the surface of the halfspace at frequencies of $5 \mathrm{~Hz}$ and $20 \mathrm{~Hz}$. At $5 \mathrm{~Hz}$, the wavelength $\lambda_{\mathrm{s}}=C_{\mathrm{s}} / f=30 \mathrm{~m}$ of shear waves in the dike is much larger than the height of the dike. As a result, the Rayleigh waves penetrate into the underlying halfspace and the displacement amplitudes on the surface of the halfspace are comparable to the displacement amplitudes on the dike. 


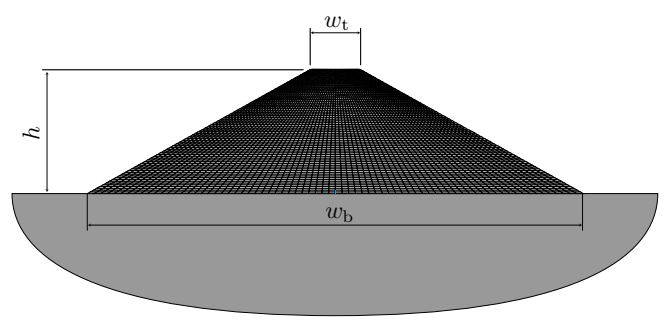

Figure 14: Mesh of the dike using 2.5D volume elements.

At a frequency of $20 \mathrm{~Hz}$, the wavelength of shear waves $\lambda_{\mathrm{s}}=C_{\mathrm{s}} / f=7.5 \mathrm{~m}$ is of the same order of magnitude as the dike height. The Rayleigh waves are now concentrated in the dike body. As a result, the dike acts as a one-dimensional wave guide. As the Rayleigh waves are trapped within the one-dimensional wave guide, the waves are only attenuated by material damping and not by geometrical damping. As a

(a)

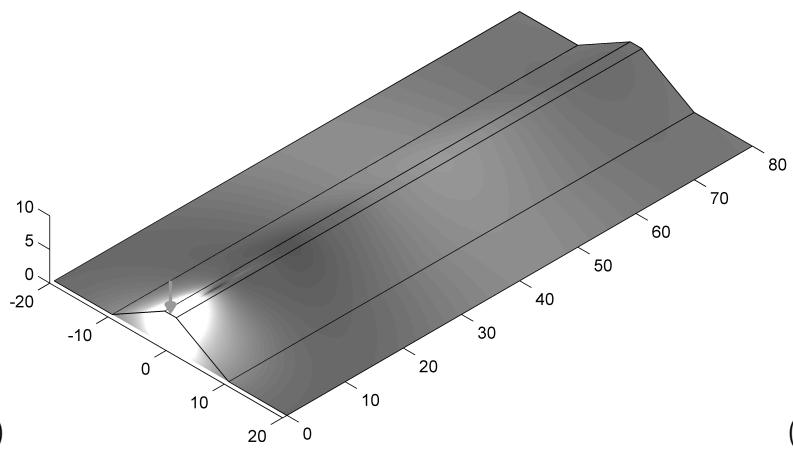

(b)

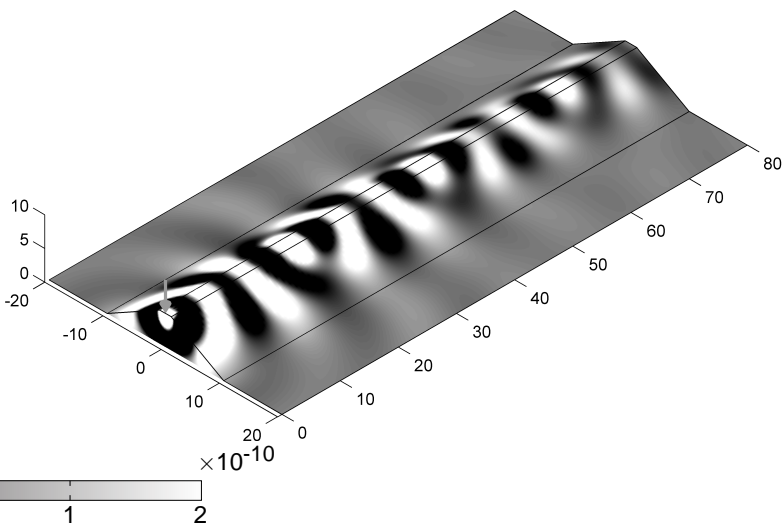

Figure 15: Real part of the vertical displacement for a unit vertical point load on top of the dike at a frequency of (a) $5 \mathrm{~Hz}$ and (b) $20 \mathrm{~Hz}$.

result, the amplitude of the Rayleigh waves in the one-dimensional wave guide is much larger than the amplitude in the equivalent halfspace. However, the dispersive character of the Rayleigh waves remains unchanged and it can be concluded that the halfspace is a good forward model to determine the dynamic soil characteristics of dikes.

\subsection{Vibration isolating screen}

In the fourth example, the 2.5D coupled FE-BE methodology is applied to study the efficiency of a vibration isolating screen in the soil. A vibration isolating screen is a soft or stiff wave barrier. Due to the impedance contrast between the isolating screen and the soil, waves are reflected, effectively reducing vibration levels behind the screen.

Figure 16 shows a vibration isolating screen embedded in a homogeneous halfspace with a shear wave velocity $C_{\mathrm{s}}=150 \mathrm{~m} / \mathrm{s}$, a dilatational wave velocity $C_{\mathrm{p}}=300 \mathrm{~m} / \mathrm{s}$, a density $\rho=1800 \mathrm{~kg} / \mathrm{m}^{3}$ and a material damping ratio $\beta_{\mathrm{s}}=\beta_{\mathrm{p}}=0.05$ in both deviatoric and volumetric deformation. The incident wavefield is generated by a unit vertical point load acting on the surface of the halfspace at a distance of $5 \mathrm{~m}$ from the vibration isolating screen.

First, the reference case of a unit point load on the surface of a homogeneous halfspace is considered. This case corresponds to the 3D Green's displacements of a layered halfspace and is evaluated by means of the direct stiffness method $[20,21,29]$. Figure 17 shows the real part of the vertical displacement due to a vertical point source on the surface of the halfspace at $20 \mathrm{~Hz}$ and $40 \mathrm{~Hz}$. The origin of the Cartesian frame of reference corresponds to the source location. 


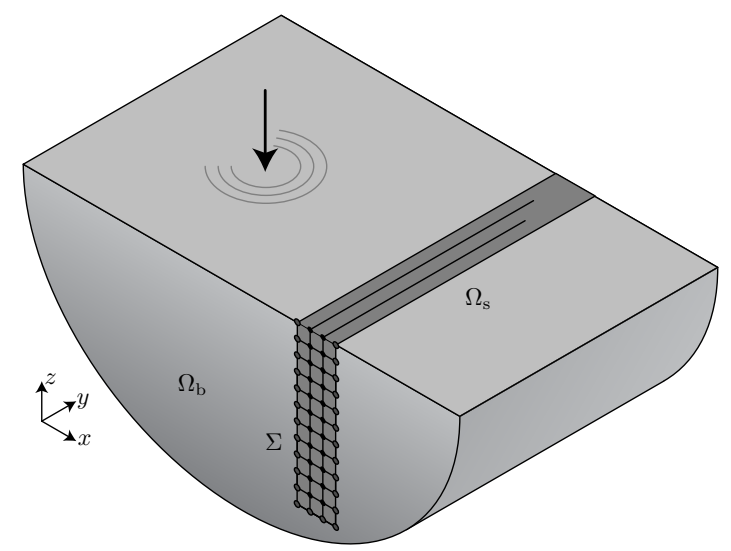

Figure 16: 2.5D methodology for the computation of the vibration isolating screen.

(a)

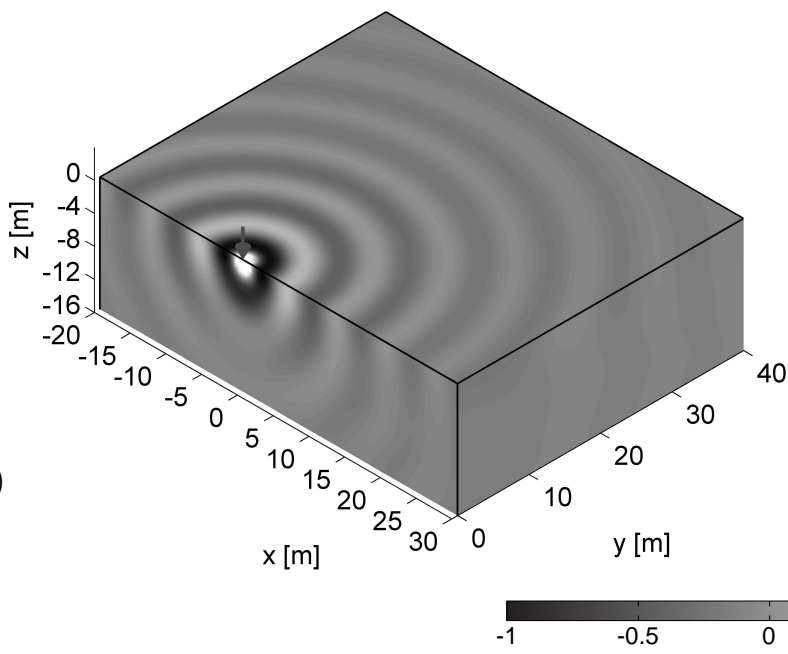

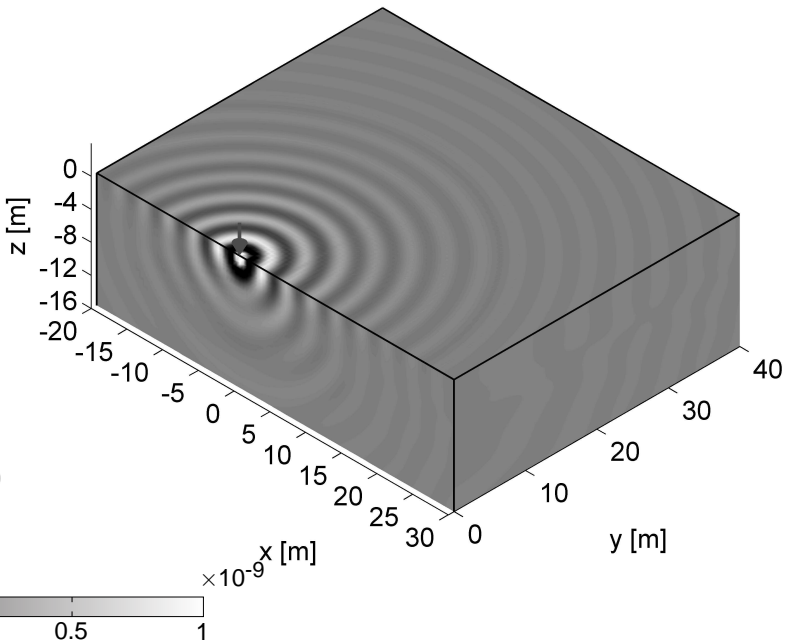

Figure 17: Real part of the vertical displacement for a unit vertical point load at the surface of a homogeneous halfspace at a frequency of (a) $20 \mathrm{~Hz}$ and (b) $40 \mathrm{~Hz}$.

The displacement in the soil is dominated by Rayleigh waves with cylindrical wave fronts. The Rayleigh waves have a velocity $C_{\mathrm{R}}=139.8 \mathrm{~m} / \mathrm{s}$ which corresponds to a wavelength $\lambda_{\mathrm{R}}=C_{\mathrm{R}} / f=6.95 \mathrm{~m}$ at the frequency $f=20 \mathrm{~Hz}$ and $\lambda_{\mathrm{R}}=3.48 \mathrm{~m}$ at a frequency $f=40 \mathrm{~Hz}$. The penetration depth of the Rayleigh waves is proportional to the wavelength: most of the wave energy is located above a depth of one wavelength. The design of the vibration isolating screen is based on this penetration depth at the lowest frequency for which isolation is desired. A concrete vibration isolating screen with a depth of $8 \mathrm{~m}$ and a width of $0.6 \mathrm{~m}$ is considered, which is expected to isolate vibrations above a frequency of $20 \mathrm{~Hz}$. The concrete has a Young's modulus $E_{\mathrm{c}}=30 \mathrm{GPa}$, a Poisson's ratio $\nu_{\mathrm{c}}=0.2$ and a density $\rho_{\mathrm{c}}=2600 \mathrm{~kg} / \mathrm{m}^{3}$. The screen is modelled with 4 -node rectangular 2.5D finite volume elements. The finite element mesh consists of 16 elements over the height of the trench and 4 elements over the width of the trench. The boundary element mesh matches the finite element mesh over the screen-soil interface, allowing for the computation of the response of the screen and the soil by means of equation (44).

A vertical point source is considered at the surface of the halfspace at a distance of $5 \mathrm{~m}$ from the centerline of the trench. Figure 18 shows the real part of the vertical displacement in the free field at frequencies of $20 \mathrm{~Hz}$ and $40 \mathrm{~Hz}$. The incident waves are reflected on the vibration isolating screen, reducing vibration levels behind the screen. At $40 \mathrm{~Hz}$, two lines of destructive interference between a direct and reflected Rayleigh 
waves are observed. As the concrete is much stiffer than the soil, it acts as a rigid wave barrier and a small displacement amplitude is observed along the soil-screen interface.

(a)

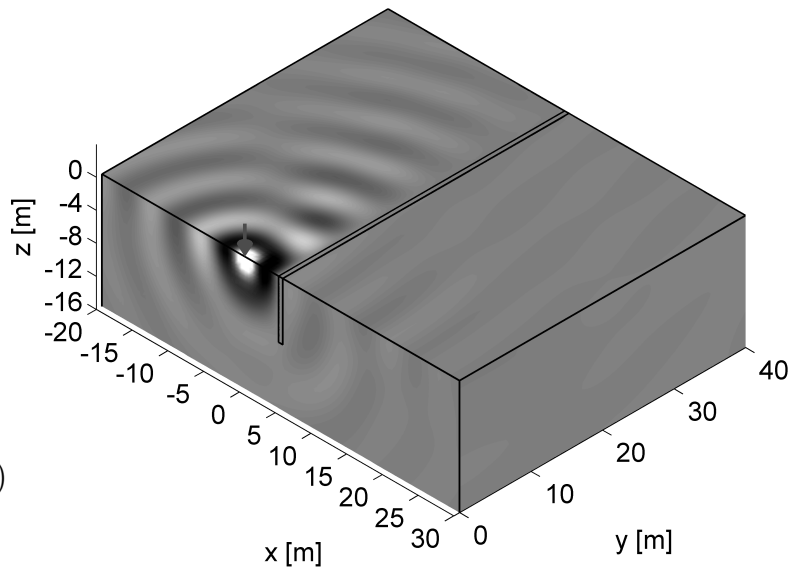

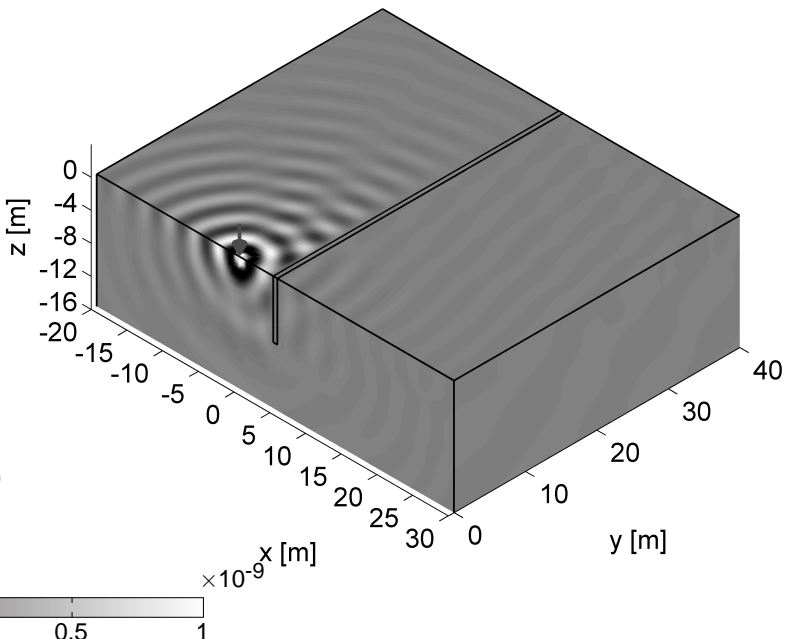

Figure 18: Real part of the vertical displacement for a unit harmonic point load at a distance of $5 \mathrm{~m}$ from the center of the concrete vibration isolating screen at a frequency of (a) $20 \mathrm{~Hz}$ and (b) $40 \mathrm{~Hz}$.

The efficiency of the vibration isolating screen can also be quantified by the insertion loss $\mathrm{IL}_{z}$ of the vertical displacement, defined as the ratio of the vertical displacement amplitudes $\left|u_{z}^{\text {iso }}(\omega)\right|$ and $\left|u_{z}^{\text {uniso }}(\omega)\right|$ in the case with and without vibration isolating screen. The vertical insertion loss is expressed in $\mathrm{dB}$ :

$$
\mathrm{IL}_{z}=20 \log _{10}\left(\frac{\left|u_{z}^{\text {uniso }}(\omega)\right|}{\left|u_{z}^{\text {iso }}(\omega)\right|}\right)
$$

Figure 19 shows the vertical insertion loss at $20 \mathrm{~Hz}$ and $40 \mathrm{~Hz}$. The screening efficiency is larger at $40 \mathrm{~Hz}$ than at $20 \mathrm{~Hz}$. This indicates that the vibration isolating screen effectively reduces the vibration levels behind the trench.

(a)

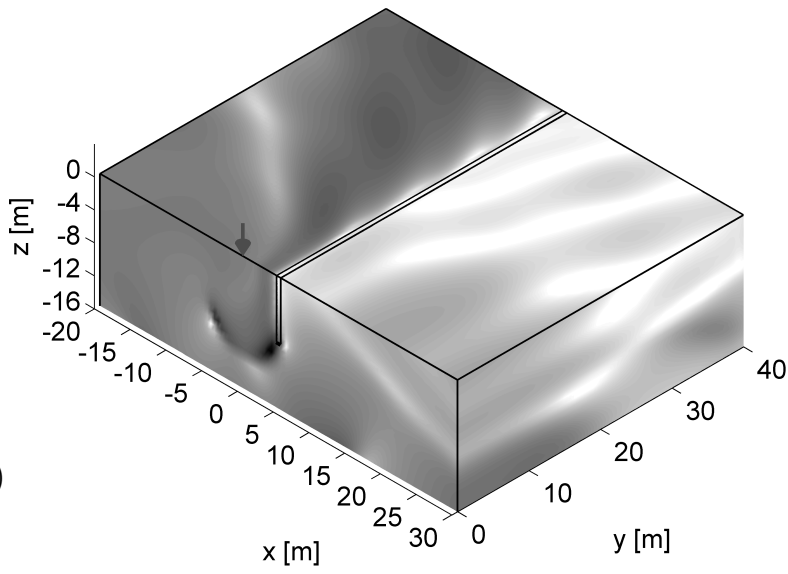

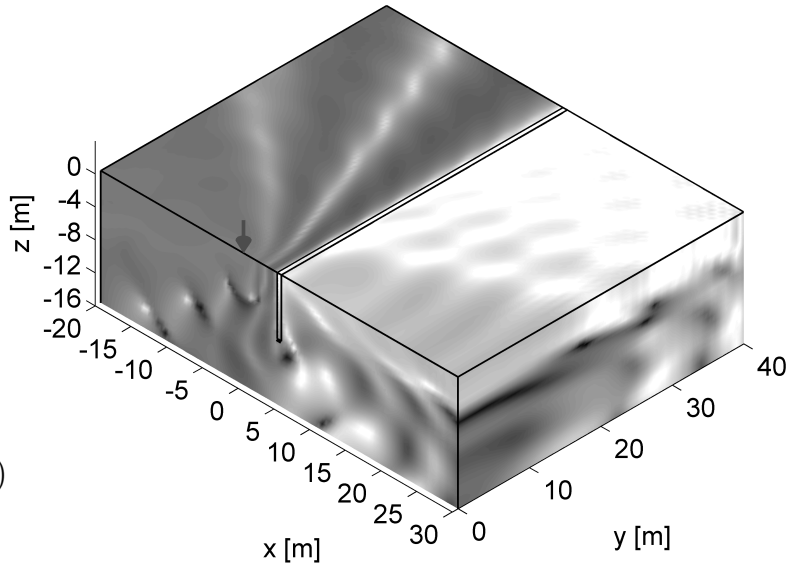

$-20$

Figure 19: Vertical insertion loss $\mathrm{IL}_{z}$ for a unit harmonic point load at a distance $d=5 \mathrm{~m}$ from the vibration isolating screen at a frequency of (a) $20 \mathrm{~Hz}$ and (b) $40 \mathrm{~Hz}$ for a concrete vibration isolating screen. 


\section{Conclusion}

In the present paper, a general 2.5D coupled FE-BE methodology for the computation of the interaction between longitudinally invariant structures and a layered halfspace has been presented. For the boundary element model, a novel regularized 2.5D boundary integral equation has been derived based on the twodimensional rigid body identity. This regularization procedure avoids the evaluation of strongly singular integrals and has been validated for a cylindrical cavity embedded in a full space. Furthermore, the boundary element method is based on the fundamental solutions of a layered halfspace which are computed by means of the direct stiffness method. As a result, only the interface between the structure and the soil has to be discretized, reducing storage requirements with respect to the classical use of full space solutions. The Green's functions are interpolated from a receiver grid that is concentrated around the source of the Green's function to the boundary element integration points for the calculation of the boundary element system matrices.

The method has been demonstrated with four examples: a road on the surface of a halfspace, a tunnel embedded in a layered halfspace, a dike on a halfspace and a vibration isolating screen in the soil.

All examples focus on the computation of the transfer function between a vertical point source and the displacements of the structure and in the soil. These transfer functions can subsequently be used to compute the response due to a moving load [24]. The examples demonstrate the practical use of the 2.5D method for the evaluation of the 3D radiated wavefield in practical dynamic soil-structure interaction problems.

\section{Acknowledgements}

The results presented in this paper have been obtained within the frame of the SBO project IWT 03175 "Structural damage due to dynamic excitation: a multi- disciplinary approach". This project is funded by IWT Vlaanderen, the Institute of the Promotion of Innovation by Science and Technology in Flanders. The first two authors are postdoctoral research fellows of the "Fonds voor Wetenschappelijk Onderzoek Vlaanderen (FWO)" or the Research Foundation Flanders. The authors gratefully acknowledge financial support from these institutes. P. Galvín is pleased to acknowledge support from the Ministerio de Ciencia e Innovación of Spain under the grant JC2008-00136.

\section{References}

[1] L. Andersen and C.J.C. Jones. Coupled boundary and finite element analysis of vibration from railway tunnelsa comparison of two- and three-dimensional models. Journal of Sound and Vibration, 293:611-625, 2006.

[2] L. Andersen and S.R.K. Nielsen. Reduction of ground vibration by means of barriers or soil improvement along a railway track. Soil Dynamics and Earthquake Engineering, 25:701-716, 2005.

[3] D. Aubry, D. Clouteau, and G. Bonnet. Modelling of wave propagation due to fixed or mobile dynamic sources. In N. Chouw and G. Schmid, editors, Workshop Wave '94, Wave propagation and Reduction of Vibrations, pages 109-121, Ruhr Universität Bochum, Germany, December 1994.

[4] D.E. Beskos, T. Krauthammer, and I. Vardoulakis, editors. Dynamic soil-structure interaction. A.A. Balkema, 1984.

[5] M. Bonnet. Boundary integral equation methods for solids and fluids. John Wiley and Sons, Chichester, United Kingdom, 1995.

[6] J. Borgions and B. Thyssen. Trillingsisolerende schermen. Master's thesis, Department of Civil Engineering, K.U.Leuven, 2008.

[7] H.D. Bui, B. Loret, and M. Bonnet. Régularisation des équations intégrales de l'élastodynamique et de l'élastostatique. Comptes Rendus de l' Académie des Sciences: série II, t.300(14):633-636, 1985.

[8] H. Chebli, R. Othman, D. Clouteau, M. Arnst, and G. Degrande. 3D periodic BE-FE model for various transportation structures interacting with soil. Computers and Geotechnics, 35:22-32, 2008.

[9] J. Domínguez. Boundary elements in dynamics. Computational Mechanics Publications and Elsevier Applied Science, Southampton, United Kingdom, 1993.

[10] A.C. Eringen and E.S. Suhubi. Elastodynamics, Volume 2, Linear theory. Academic Press, New York, USA, 1975.

[11] J.A. Forrest and H.E.M. Hunt. Ground vibration generated by trains in underground tunnels. Journal of Sound and Vibration, 294:706-736, 2006.

[12] J.A. Forrest and H.E.M. Hunt. A three-dimensional tunnel model for calculation of train-induced ground vibration. Journal of Sound and Vibration, 294:678-705, 2006.

[13] S. François, M. Schevenels, and G. Degrande. Applicability of the MASW method on dykes. Report BWM-2007-06, Department of Civil Engineering, K.U.Leuven, March 2007. Report to Geotomographie Gmbh. 
[14] L. Gavrić. Finite element computation of dispersion properties of thin-walled structures. Journal of Sound and Vibration, 173(1):113-124, 1994.

[15] L. Gavrić. Computation of propagative waves in free rail using finite element technique. Journal of Sound and Vibration, 183(3):531-543, 1995.

[16] S. Gupta, M.F.M. Hussein, G. Degrande, H.E.M. Hunt, and D. Clouteau. A comparison of two numerical models for the prediction of vibrations from underground railway traffic. Soil Dynamics and Earthquake Engineering, 27(7):608-624, 2007.

[17] M.F.M. Hussein, S. Gupta, H.E.M. Hunt, G. Degrande, and J.P. Talbot. A computationally efficient model for calculating vibration from a railway tunnel buried in a half-space. International Journal for Numerical Methods in Engineering, 2010. Submitted for publication.

[18] M.F.M. Hussein, L. Rikse, S. Gupta, H.E.M. Hunt, G. Degrande, J.P. Talbot, S. François, and M. Schevenels. Using the PiP model for fast calculation of vibration from a railway tunnel in a multi-layered half-space. In 9th International Workshop on Railway Noise, Munich, Germany, September 2007.

[19] L. Karl, Fechner T., G. Degrande, and S. François. Application of surface waves for the geotechnical characterisation of dykes. In Near Surface 2008, 14 th European meeting of environmental and Engineering Geophysics, Kraków, Poland, Sepember 2008.

[20] E. Kausel. Fundamental solutions in elastodynamics: a compendium. Cambridge University Press, New York, 2006.

[21] E. Kausel and J.M. Roësset. Stiffness matrices for layered soils. Bulletin of the Seismological Society of America, 71(6):1743-1761, 1981.

[22] G. Lombaert. Development and experimental validation of a numerical model for the free field vibrations induced by road traffic. PhD thesis, Department of Civil Engineering, K.U.Leuven, 2001.

[23] G. Lombaert and G. Degrande. Experimental validation of a numerical prediction model for free field traffic induced vibrations by in situ experiments. Soil Dynamics and Earthquake Engineering, 21(6):485-497, 2001.

[24] G. Lombaert, G. Degrande, and D. Clouteau. Numerical modelling of free field traffic induced vibrations. Soil Dynamics and Earthquake Engineering, 19(7):473-488, 2000.

[25] G. Lombaert, G. Degrande, J. Kogut, and S. François. The experimental validation of a numerical model for the prediction of railway induced vibrations. Journal of Sound and Vibration, 297(3-5):512-535, 2006.

[26] G. Lombaert, G. Degrande, B. Vanhauwere, B. Vandeborght, and S. François. The control of ground borne vibrations from railway traffic by means of continuous floating slabs. Journal of Sound and Vibration, 297(3-5):946-961, 2006.

[27] J.E. Luco and H.L. Wong. Seismic response of foundations embedded in a layered half-space. Earthquake Engineering and Structural Dynamics, 15:233-247, 1987.

[28] F.J. Rizzo, D.J. Shippy, and M. Rezayat. A boundary integral equation method for radiation and scattering. International Journal for Numerical Methods in Engineering, 21:115-129, 1985.

[29] M. Schevenels, S. François, and G. Degrande. EDT: An ElastoDynamics Toolbox for MATLAB. Computers and Geosciences, 2009. Accepted for publication.

[30] X. Sheng, C.J.C. Jones, and M. Petyt. Ground vibration generated by a harmonic load acting on a railway track. Journal of Sound and Vibration, 225(1):3-28, 1999.

[31] X. Sheng, C.J.C. Jones, and D.J. Thompson. Modelling ground vibrations from railways using wavenumber finite- and boundary-element methods. Proceedings of the Royal Society, 461:2043-2070, 2005.

[32] X. Sheng, C.J.C. Jones, and D.J. Thompson. Prediction of ground vibration from trains using the wavenumber finite and boundary element methods. Journal of Sound and Vibration, 293:575-586, 2006.

[33] A.A. Stamos and D.E. Beskos. 3-D seismic response analysis of long lined tunnels in half-space. Soil Dynamics and Earthquake Engineering, 15:111-118, 1996.

[34] A.J.B. Tadeu, J.M.P. Antonio, and E. Kausel. 3D scattering of waves by a cylindrical irregular cavity of infinite length in a homogeneous elastic medium. Computer Methods in Applied Mechanics and Engineering, 191:3015-3033, 2002.

[35] A.J.B. Tadeu and E. Kausel. Green's functions for two-and-a-half-dimensional elastodynamic problems. ASCE Journal of Engineering Mechanics, 126(10):1093-1096, 2000. 